\title{
Transmissão de energia mecânica por meio de correias flexíveis
}

\author{
David Lira Nunez ${ }^{1}$ \\ ${ }^{1}$ Federal University of Technology - Paraná (UTFPR)
}

31 de julho de 2022

\section{Resumo}

Uma grande quantidade de equipamentos é acionada por motores elétricos que transmitem uma determinada rotação e torque por meio de sistemas de transmissão flexíveis, especificamente pelo uso de correias. Estas apresentam, no seu perfil transversal, o formato em V, mas também existem correias que, comparadas com as de formato em $\mathrm{V}$, oferecem maior precisão de rotação entre o sistema de acionamento e o sistema acionado, ou seja, sincronizam a rotação durante a partida, o funcionamento e a parada da máquina, e é daí o nome do segundo tipo de correias de transmissão flexíveis, as correias síncronas ou sincronizadoras. Embora as correias sejam um elemento mecânico de suma importância na nossa atualidade, poucas atualizações foram encontradas na literatura consolidada dos cursos de Engenharia Mecânica, forçando em alguns casos a seguir o procedimento de cálculo errado ou desatualizado para a seleção de um tipo de correia, não levando em consideração o que se encontra disponível na atualidade. Nesse sentido, esta publicação busca apresentar os cálculos consolidados da literatura acadêmica para a seleção correta de uma correia flexível e atualizar os mesmos com gráficos e fatores padronizados pelos principais fabricantes desse tipo de elemento de transmissão mecânica. Também são abordadas as principais normas internacionais usadas para a fabricação de correias e suas respectivas polias. Finalmente, com o intuito de consolidar o procedimento de cálculo de uma correia de transmissão, é apresentado um estudo de caso que busca a seleção da melhor correia flexível.

\section{Introdução}

Para [1], o acionamento de máquinas como compressores, máquinas-ferramentas, laminadores de metais e motores de automóveis, entre outros, usando correias flexíveis de transmissão, tem a característica de isolar impactos durante o funcionamento das máquinas, oferecer distâncias graduáveis de funcionamento entre eixos de transmissão, além de tolerar graus de desalinhamento entre eixos maior do que uma engrenagem, por exemplo. As correias são fabricadas com 
superfícies de borracha sintética para aumentar o coeficiente de atrito quando instaladas nos canais de uma polia. As correias de transmissão internamente podem ser reforçadas com fibras, cabos, cordas ou cintas, para suportar a tração exercida durante o acionamento e funcionamento de uma máquina.

Para [2], devem ser considerados alguns valores máximos para correias flexíveis de transmissão: potência máxima $1100 \mathrm{~kW}$, relação de transmissão até 1:8.

A velocidade linear de uma correia geralmente deve estar no intervalo de $13 \mathrm{~m} / \mathrm{s} \mathrm{a} 33 \mathrm{~m} / \mathrm{s}$, consequentemente a velocidade angular deve ser relativamente alta, o que mitiga a força de tração contínua. Quando a velocidade linear for muito baixa, pode comprometer negativamente a tensão na correia, como também gerar desgastes prematuros nas superfícies de contato pelo constante deslizamento dos elementos, canal da polia e correia. Por outro lado, superar as velocidades recomendadas de projeto pode acionar de forma negativa a força centrífuga, provocando vibrações e o chicotear da correia que comprometem negativamente a sua vida útil remanescente (RUL - do inglês Remaining Useful Life). Nesse sentido, normalmente se recomenda o trabalho a uma velocidade linear próxima de $20 \mathrm{~m} / \mathrm{s}$, e caso a velocidade seja inferior a $13 \mathrm{~m} / \mathrm{s}$, deve ser considerada a transmissão por correia sincronizadora; a velocidade linear recomendada para uma correia sincronizada é de aproximadamente $\mathbf{1 0} \mathbf{~ m} / \mathbf{s}$ [3].

Durante a transmissão a correia que está em volta da polia tem um lado tensionado fruto da tração tangencial que produz com a polia e, nesse mesmo intervalo de tempo, existe um outro lado da correia que está frouxo, ver Figura 8. Após a primeira hora de funcionamento da correia, recomenda-se que haja uma verificação do tensionamentos da mesma, seguindo recomendações do fabricante de correias. Além disso, [3] estima que uma correia tem aproximadamente uma RUL entre 5000 a 7000 horas (aproximadamente entre 7 a 10 meses), e as polias uma vida útil de 25000 horas (aproximadamente 2 anos e 10 meses).

Por outro lado, em comparação às correias em $\mathrm{V}$, as sincronizadoras tem uma menor exigência à tração no início da partida do sistema e também durante seu funcionamento o lado tensionado da correia é menos tracionado quando comparado ao da correia em V. A correia sincronizadora ou síncrona possui frisos equidistantes que engatam perfeitamente em ranhuras de uma polia dentada, conseguindo uma sincronização efetiva de transmissão. Além disso, possui baixas velocidades de operação para o mesmo tipo de aplicação quando comparadas com as correias em V [3]. 


\section{Tipos de correias}

A seguir são apresentados os tipos de correias mais usados na indústria a partir do catálogo da [4] e [5]. Cabe registrar que além desses fabricantes existem vários outros que disponibilizam esse tipo de correias, já que são padronizadas por normas. Além disso, cada fabricante desenvolve outros tipos de correias que devem ser consultados com mais detalhamento, caso seja necessário.

\subsection{Correia em V clássicas:}

Essas correias apresentam um perfil clássico em V e a sua geometria é fabricada seguindo a norma [6] para oferecer um rendimento confiável em todas as transmissões industriais de seção clássica. São usadas geralmente em: compressores, bombas, alternadores, serras, moinhos, máquinas de processos, entre outros equipamentos. Cordas de tração de poliéster robustos proporcionam resistência a forças de flexão, fadiga e altas cargas. Caso sejam destinadas ao uso em ambientes explosivos ou em situações em que há risco de incêndio, e seja necessário que tenham a característica de poderem dissipar as cargas elétricas, devem ser fabricadas seguindo a norma [7] . Estas correias possuem uma proteção na sua superfície que isola óleos que possam causar problemas de aderência, além de protegê-las contra a abrasão. Suportam temperaturas de $-30{ }^{\circ} \mathrm{C}$ a $70{ }^{\circ} \mathrm{C}$.

Esse tipo de correias funciona para polias que seguem a norma [8], onde são especificadas as principais características dimensionais dos perfis para polias em $\mathrm{V}$ clássicas. As correias clássicas em V podem ser encontradas nas seções: A (com comprimentos de passo de 541 a 5 $113 \mathrm{~mm}$ ), B (com comprimentos de 655 a $13358 \mathrm{~mm}$ ), C (com comprimentos de 1191 a 11 $453 \mathrm{~mm}$ ), D (com comprimentos de 2370 a $16848 \mathrm{~mm}$ ), E (com comprimentos de 3772 a 16 $789 \mathrm{~mm}$ ) e Z (com comprimentos de 435 a $1825 \mathrm{~mm}$ ).

Em alguns projetos há a necessidade de mais de um mesmo tipo de correia. Para esses casos, podem ser encontradas correias que já vêm de fábrica com o número de correias unidas, conhecidas como poly V. Nesse caso, antes da letra, que determina a seção da correia, deve ser informado o número de correias necessárias. Para aplicações industriais normalmente esta configuração é encontrada para as seções A, B, C e D, i.e., se precisa-se de 4 correias seção B, pode ser solicitado uma correia $4 \mathrm{~B}$.

Ainda podem ser encontradas correias clássicas com seção Y mas, não se recomenda mais seu uso visto que as polias para esse tipo de correia podem ter polias com diâmetros de passo pequenos, podendo degradar rapidamente a vida útil da correia. Para esses casos, quando o diâmetro da polia é pequeno, recomenda-se usar correias dentadas ou chamadas de correias em 
V estreitas. Na Figura 1 são apresentadas as medidas das correias clássica em V.

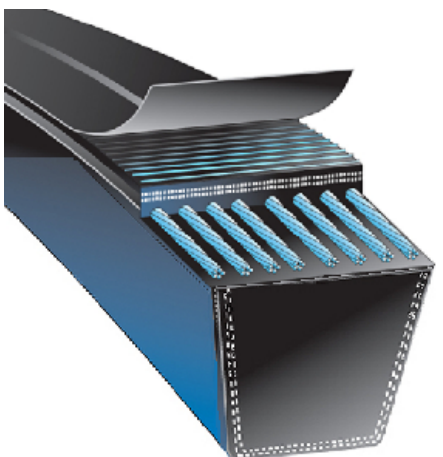

Clássica em $\mathrm{V}$

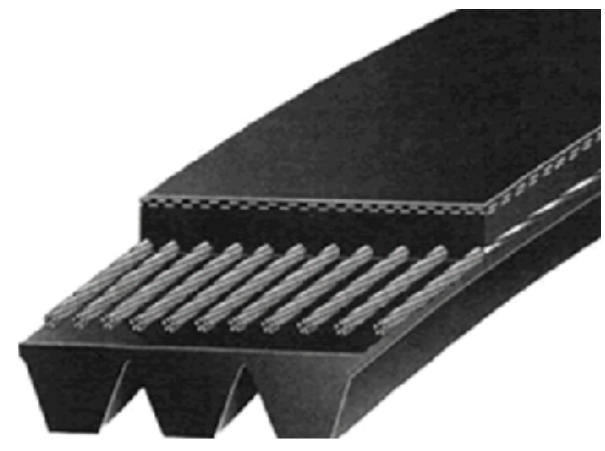

Poly V

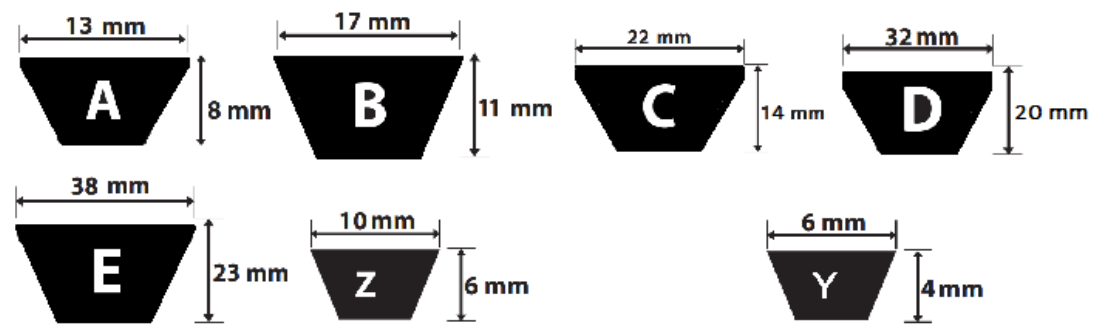

Figura 1: Correias em V clássicas

\subsection{Correia em V estreitas}

Essas correias transmitem mais potência a altas velocidades para polias com diâmetros pequenos. Ideais para aplicações industriais pesadas, essas correias também são fabricadas seguindo a norma [6]. Seu seccionamento dentado permite se adaptar a circunferências pequenas, distribuindo de forma efetiva a tensão térmica e de flexão, e na sua fabricação também podem seguir a norma [7]. Além disso, permitem um funcionamento mais suave e silencioso, com menos deslizamento e desgaste da correia. Normalmente trabalham no intervalo de temperatura de $-30^{\circ} \mathrm{C}$ a $60^{\circ} \mathrm{C}$.

Esse tipo de correia funciona para polias que seguem a norma [8], que especifica as principais características dimensionais dos perfis para polias em $\mathrm{V}$ estreitas. Os perfis podem ser encontrados nas seções: SPA (com comprimentos de 1700 a $4500 \mathrm{~mm}$ ), SPB (com comprimentos de 2990 a $8000 \mathrm{~mm}$ ), SPC (com comprimentos de 2000 a $11200 \mathrm{~mm}$ ) e SPZ (com comprimentos de 3000 a $3550 \mathrm{~mm})$.

Outro tipo de correia estreita são as de seção: 3V (com comprimentos efetivo de 1143 a 3556 $\mathrm{mm}$ ), $5 \mathrm{~V}$ (com comprimentos efetivo de 1524 a $9017 \mathrm{~mm}$ ) e $8 \mathrm{~V}$ (com comprimentos efetivo de 2540 a $15240 \mathrm{~mm}$ ). Esse tipo de correia funciona para polias que seguem a norma [9] 
ou [10], que especifica as principais características dimensionais dos perfis para polias em V estreitas. Na Figura 2 são apresentadas as medidas das correias estreitas em V.

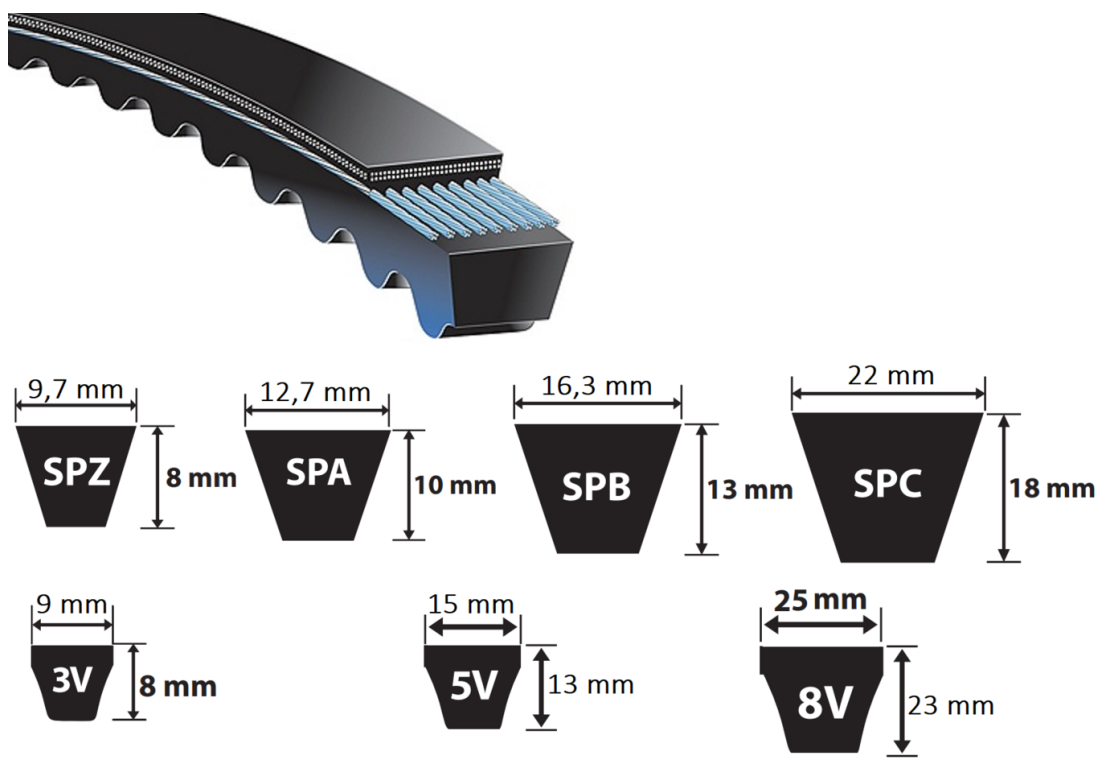

Figura 2: Correias em V estreitas

A seguir é apresentada uma imagem na Figura 3 com medidas definidas pelas normas [8] e [10]. Esses valores foram extraídos do programa de Projeto Assistido por Computador (CAD - do inglês Computer-Aided Design), [11].

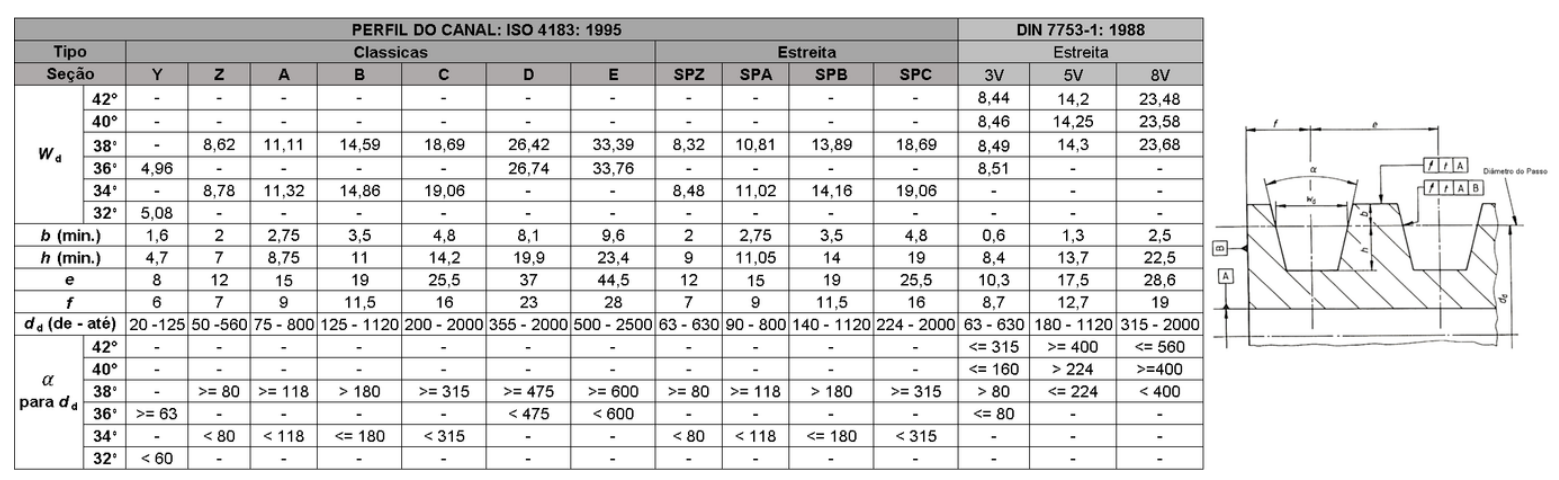

Figura 3: Geometria de polias clássicas e estreitas

\subsection{Correia em V ângulo duplo}

Correias projetadas para sistemas que precisam de transmissão em ambos os lados da correia. Uso para várias aplicações industriais onde o sistema de transmissão precisa de inversão de 
rotação. $\mathrm{O}$ seu formato proporciona um contato completo com o canal da polia e são resistentes ao óleo, calor e à condutividade estática. Suportam intervalos de temperatura de $-30^{\circ} \mathrm{C} \mathrm{a} 60^{\circ} \mathrm{C}$ Estão disponíveis na seção AA (com comprimentos efetivo de 1349 a 53812 mm), BB (com comprimentos efetivo de 963 a $7656 \mathrm{~mm}$ ), CC (com comprimentos efetivo de 2011 a 10723 $\mathrm{mm}$ ) e DD (com comprimentos efetivo de 6926 a $9212 \mathrm{~mm}$ ). A Figura 4 ilustra as principais características desse tipo de correias.
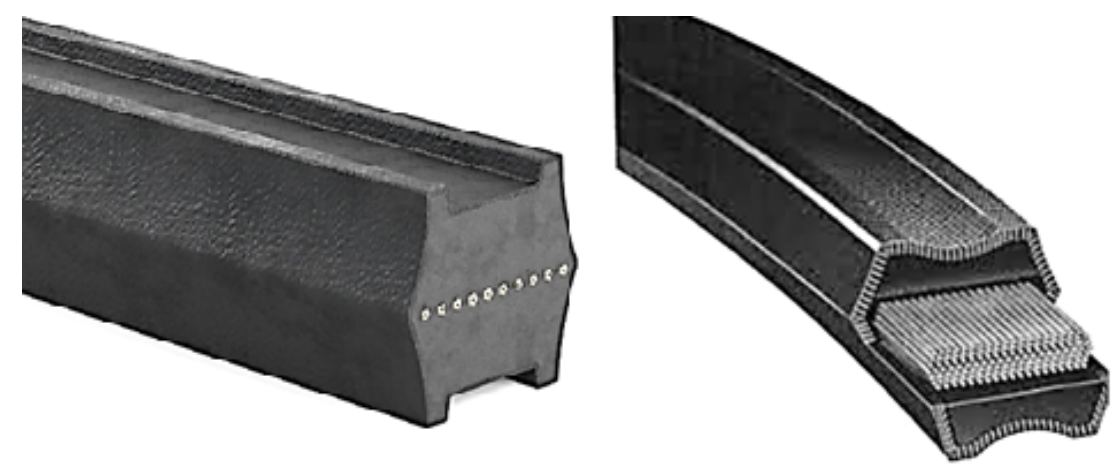

Figura 4: Correias em V de ângulo duplo

\subsection{Correias Micro-V Industriais}

Essas correias se adaptam a equipamentos eléctricos de exteriores, transportadores de rolos, máquinas ferramentas, entre outros. Possuem boa resistência à água, óleo e calor e são silenciosas. Os canais alternados permitem uma maior flexibilidade, diminuindo a concentração de calor e melhorando a resistência a fissuras, diferentemente das poly- $\mathrm{V}$, estas podem ser usadas em polias de pequenos diâmetros, e também em uma polia com canais ou sem canais. Podem ser encontradas com ranhuras de 4 a 324.

Esse tipo de correias funciona para polias que seguem a norma [12], que especifica as principais características dimensionais dos perfis de ranhura para polias com nervuras em $\mathrm{V}$, correspondentes as seções PJ (com ranhuras de 4 a 24 e comprimento efetivo de $280 \mathrm{~mm}$ a $2489 \mathrm{~mm}$ ), PK (com 324 ranhuras e comprimento efetivo de 630 a $2845 \mathrm{~mm}$ ), PL (desde 4 a 48 ranhuras com diâmetro efetivo de 954 mm a 6093 mm) e PM (desde 4 ranhuras com diâmetro efetivo de $2286 \mathrm{~mm}$ a $15286 \mathrm{~mm}$ ). Na Figura 5 são apresentadas as medidas das correias micro-V. 

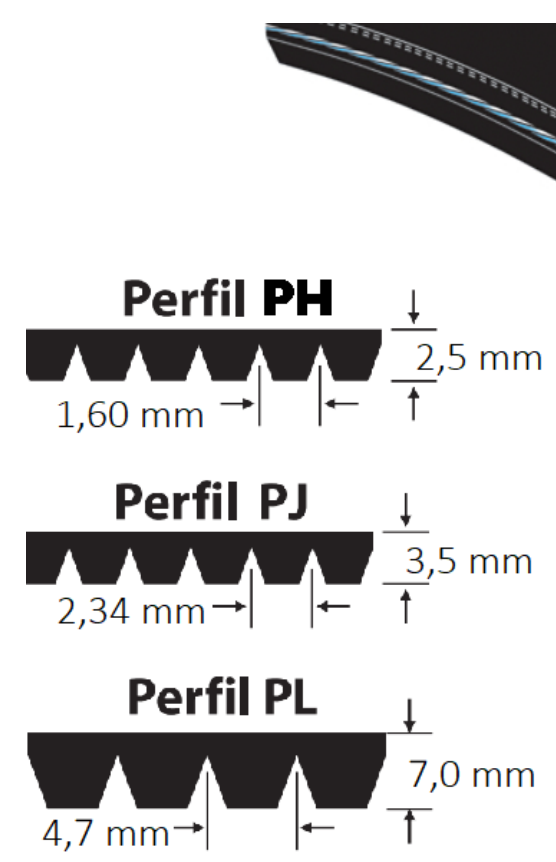

Cabos de alta tração
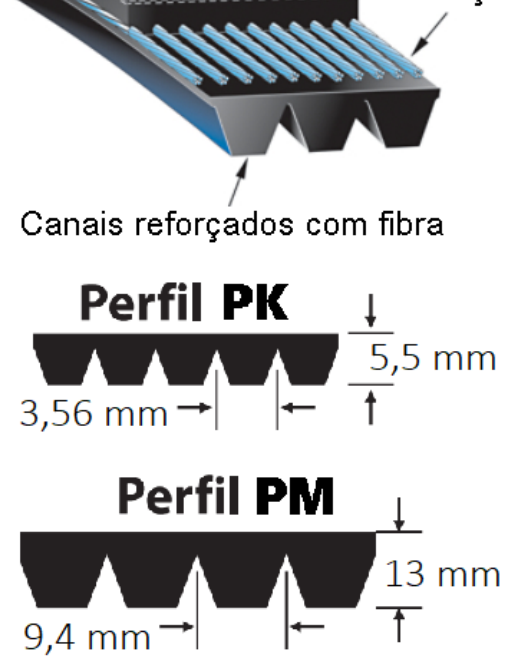

Figura 5: Correias múltiplas Micro-V

A seguir é apresentada uma imagem com medidas definidas pela norma [12]. Esses valores, também, foram extraídos do CAD, [11].

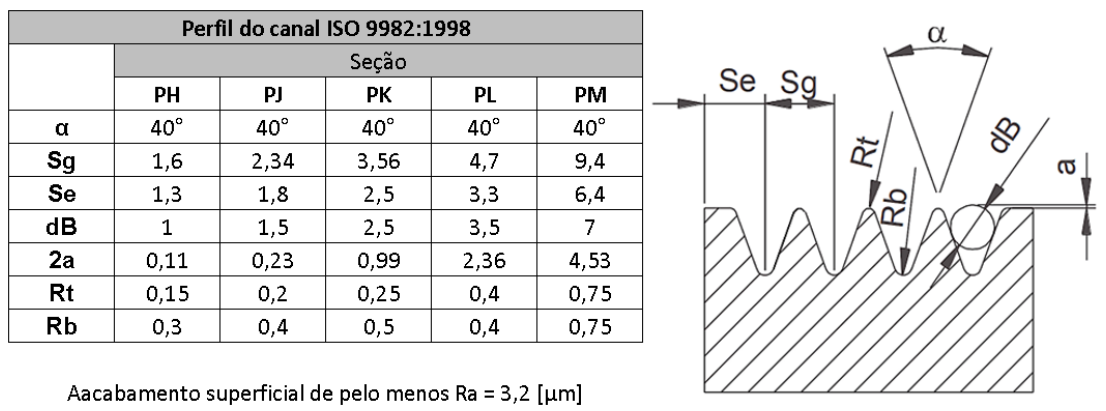

Figura 6: Geometria da polia Micro-V

\subsection{Correias síncrona}

Esse tipo de correias, oferecem pouca manutenção, são aplicadas desde o uso de uma pequena impressora até máquinas de grande porte (bombas de óleo, etc.). Seu perfil dentado trapezoidal faz com que seja adequada para aplicações onde precisam de um ótimo posicionamento. Possui reforços com cabos de fibra de vidro que evitam alongamentos. Seu corpo de neoprene oferece proteção contra sujeiras, graxas, óleos e umidade. Os dentes da correia são revestidos de nylon o que faz deles resistentes ao desgaste. 
Suportam temperaturas externas, não precisam de constantes ajustes de tensionamentos. O intervalo de temperatura que suportam é de $-30^{\circ} \mathrm{C}$ a $100^{\circ} \mathrm{C}$. Aguentam velocidades lineares de até $80 \mathrm{~m} / \mathrm{s}$ e não oferecem deslizamento.

Disponíveis em passos com seção trapezoidal MXL (com número de dentes de 36 a 681), XL (com número de dentes de 21 a 425), L (com número de dentes de 33 a 252), H (com número de dentes de 42 a 466), XH (com número de dentes de 58 a 200), XXH (com número de dentes de 56 a 144) [13]. A norma que determinava a geometria dessas até 2018 era a [14], até a atualidade a norma ISO ainda não informou qual será a substituta dessa norma. As especificações geométricas das polias e correias dentadas de formato trapezoidal podem seguir norma [15].

Também existem correias sincronizadoras, mas o perfil dos dentes não é trapezoidal e sim circular, estes podem ser encontradas em seções 3M (com número de dentes de 29 a 668), $5 \mathrm{M}$ (com número de dentes de 24 a 760), $8 \mathrm{M}$ (com número de dentes de 33 a 350), 14M (com número de dentes de 56 a 327) e 20M (com número de dentes de 100 a 330). Para sua especificação da geometria de correia e polia usa-se a norma [16]. Na Figura 7

são apresentadas as principais medidas das correias síncrona, tanto para formato circular como trapezoidal.

Para a [17], quando as correias sincronizadoras precisam ser usadas em ambientes explosivos ou em situações em que há risco de incêndio, e seja necessário que tenham a característica de poderem dissipar as cargas elétricas, devem ser fabricadas seguindo a norma [18]

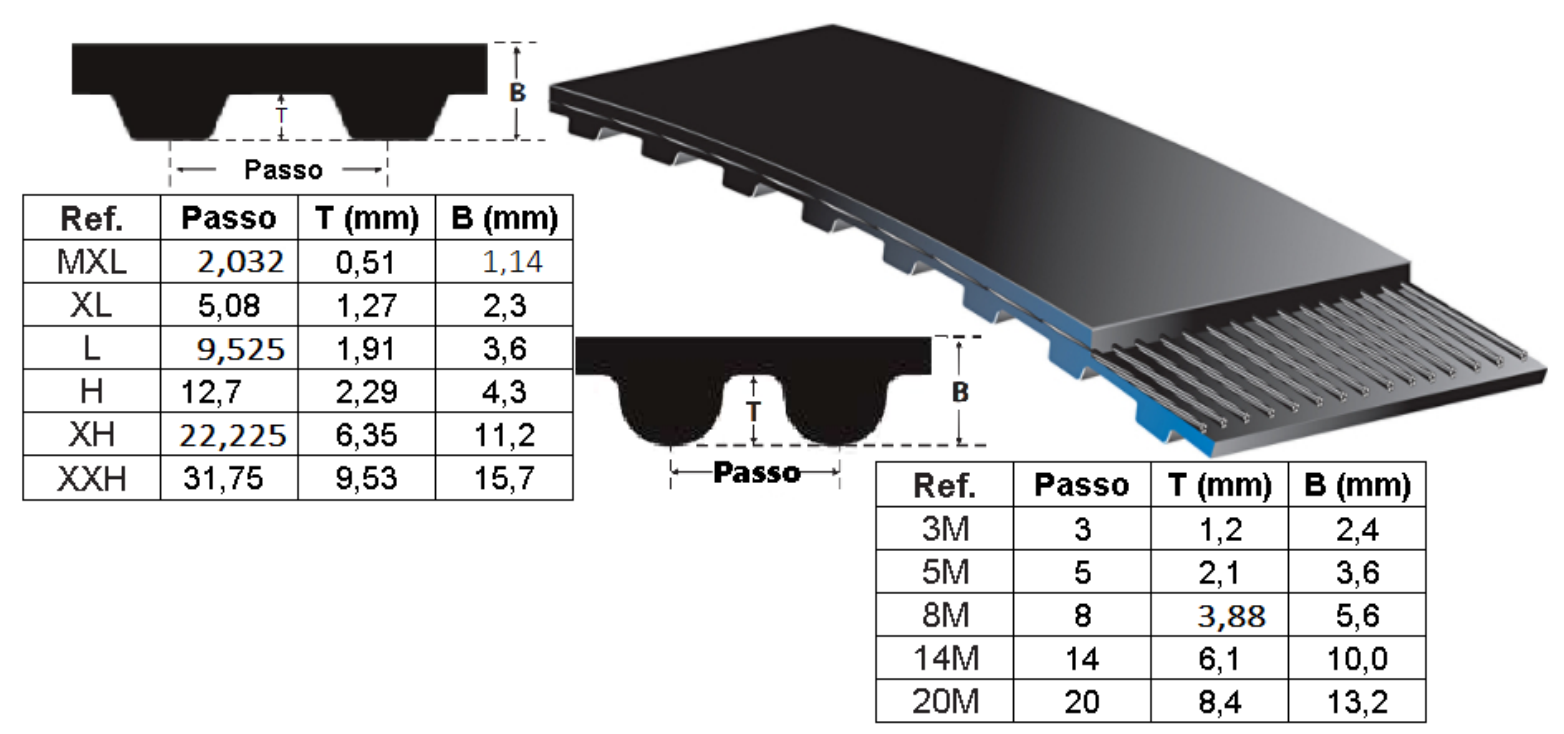

Figura 7: Correias sincronizadoras 


\section{Dimensionamento de correias de transmissão em V}

As correias com ranhura transversal que possuem perfil em $\mathrm{V}$, normalmente apresentam um ângulo dessa ranhura definido em normas que pode ser entre $34^{\circ}$ a $42^{\circ}$, conforme pode ser observado na Figura 3, e dependerá basicamente do diâmetro de passo $\left(d_{d}\right)$ [3].

O tamanho do diâmetro de uma polia é indicado pelo diâmetro de passo, $d_{d}$, levemente menor que o diâmetro exterior. A polia que gera o movimento angular é chamada de polia motriz ou motora, e a outra polia é chamada de polia movida ou acionada. Para efeitos de simplificação das equações, sempre que se referir a diâmetro de passo será escrito sem o subcrito d.

A velocidade linear na polia, considerando que não há deslizamento entre correia e canal da polia, é a mesma para a polia motriz e movida. A velocidade linear na polia pode ser encontrada usando a Equação 1 [3].

$$
V=\frac{\pi \cdot d \cdot \omega_{1}}{60000}
$$

onde a velocidade linear, $V$, em $\mathrm{m} / \mathrm{s}$; diâmetro de passo da polia, $d$, em mm; e a rotação da polia motriz, $\omega_{1}$, em rpm.

O torque do sistema motriz pode ser encontrado com a Equação 2 [19].

$$
T=\frac{P \cdot 9,55}{\omega}
$$

onde o torque, $T$, é dado em $N \cdot m$; a potência, $P$, em $W$; e a rotação, $\omega$, em rpm.

Dessa forma, o índice de velocidade, $i$, que é a relação entre as polias, pode ser encontrado com a Equação 3 [3].

$$
i=\frac{w_{1}}{w_{2}}=\frac{D}{d}
$$

onde $\omega_{1}$ é a rotação angular da polia motriz; $\omega_{2}$ a rotação da polia movida, $D$ é o diâmetro de passo da polia maior (normalmente a movida); $d$ é o diâmetro da polia menor (normalmente a polia motriz). A simbologia básica usada no cálculo de uma correia de transmissão é apresentado na Figura 8, que é uma adaptação de [19]. 


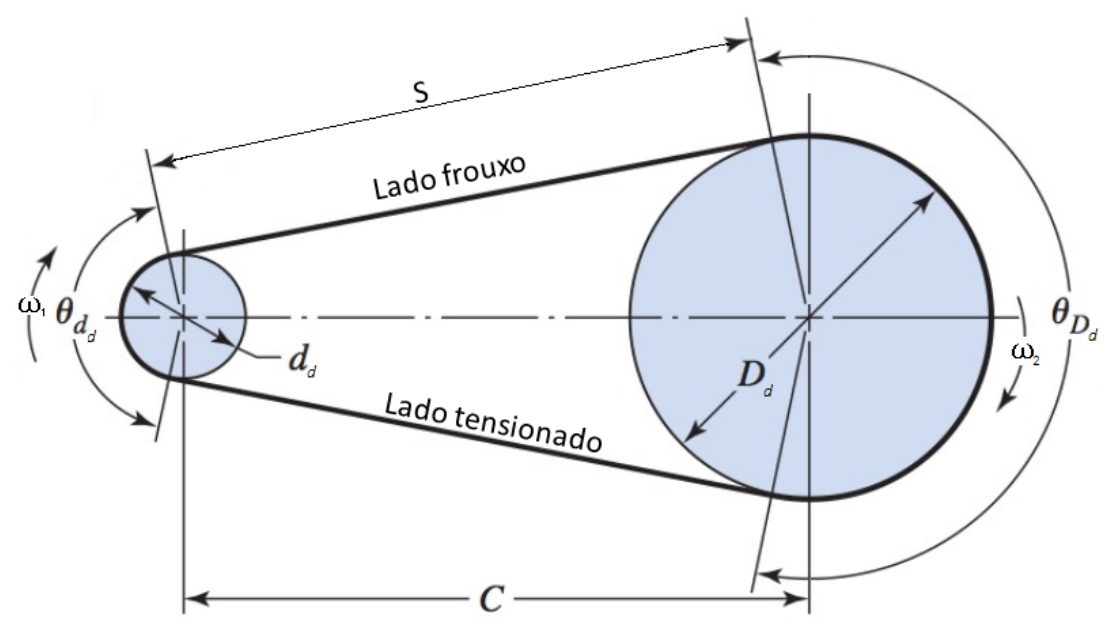

Figura 8: Geometria básica de uma transmissão por polias

Há maior tensão de trabalho no lado tensionado da correia do que no lado frouxo, porém o ponto onde ocorre a maior tensão é quando a correia entra na polia de menor diâmetro. É por esse motivo que cada tipo de correia, dependendo do formato de seção transversal, tem um diâmetro mínimo projetado para cada polia. Quanto menor diâmetro de polia, maior a degradação da correia e consequente redução da sua RUL. Durante o projeto de uma correia em V costuma-se considerar que a relação entre o lado tensionado e frouxo é de 5 [3].

Normalmente, quando projetamos correias em $\mathrm{V}$ a relação entre polia acionada e motora não deve passar o valor de 6:1. Para correias sincronizadas, essa relação pode chegar até 7:1. Caso seja necessário extrapolar essas relações, devem ser instaladas mais reduções [3].

No cálculo do comprimento da correia deve ser considerado que a mesma fique bem tracionada, por meio de tensionadores ou mancais esticadores. A folga aceitável da correia deve ser conforme recomendação do fabricante.

Um dado importante a ser considerado no início do projeto de uma correia é a potência de projeto, $P_{d}$, que é a multiplicação da potência real de entrada, $P$ (normalmente fornecida), vezes o fator de serviço, $f$, que será determinado pelo tipo de acionamento e tipo de máquina acionada, que pode ser encontrado usando a Tabela 1. Essa tabela é uma adaptação dos trabalhos de [3]; [19]; [4] .

Os valores da Tabela são para sistemas de redução, ou seja, a polia menor é a motriz. Quando o sistema tem uma relação de ampliação, os valores da Tabela 1 devem ser multiplicados por $1,2[3] ;[2]$. 
Tabela 1: Fator de serviço entre tipo de acionamento e máquina acionada para correias em $\mathrm{V}$

\begin{tabular}{|c|c|c|c|c|c|c|}
\hline & Motor & elétrico & $\begin{array}{l}\text { partida } \\
\text { leve }\end{array}$ & Motor & elétrico & $\begin{array}{l}\text { partida } \\
\text { pesada }\end{array}$ \\
\hline $\begin{array}{l}\text { Carga segundo tipo de } \\
\text { máquina acionada }\end{array}$ & $\begin{array}{l}<10 \mathrm{~h} \\
\text { por dia } \\
\text { (intermi- } \\
\text { tente) }\end{array}$ & $\begin{array}{l}10-16 \\
\mathrm{~h} \text { por dia } \\
(\text { normal) }\end{array}$ & $\begin{array}{l}>16 \mathrm{~h} \\
\text { por dia } \\
\text { (contínuo) }\end{array}$ & $\begin{array}{l}<10 \mathrm{~h} \\
\text { por dia } \\
\text { (intermi- } \\
\text { tente) }\end{array}$ & $\begin{array}{l}10-16 \\
\mathrm{~h} \text { por dia } \\
\text { (normal) }\end{array}$ & $\begin{array}{l}>16 \mathrm{~h} \\
\text { por dia } \\
\text { (contínuo) }\end{array}$ \\
\hline $\begin{array}{l}\text { Uniforme: Transportadores } \\
\text { de correai leves, bombas } \\
\text { centrífugas, compressor, ven- } \\
\text { tilador, exaustores e soprador } \\
\text { abaixo de } 7,5 \mathrm{~kW}\end{array}$ & 1,0 & 1,1 & 1,2 & 1,1 & 1,2 & 1,3 \\
\hline $\begin{array}{l}\text { Choque leve: Transportado- } \\
\text { res de correias para areia e ce- } \\
\text { reais, agitadores, bomba ro- } \\
\text { tativa, gerador, máquinas fer- } \\
\text { ramentas, misturadores, ven- } \\
\text { tilador e soprador acima de } \\
7,5 \mathrm{~kW} \text {, prensa, peneira rota- } \\
\text { tiva }\end{array}$ & 1,1 & 1,2 & 1,3 & 1,2 & 1,3 & 1,4 \\
\hline $\begin{array}{l}\text { Choque médio: Elevador de } \\
\text { canecas, máquina de tijolo, } \\
\text { bomba e compressor de } \\
\text { pistão, máquina têxtil, moin- } \\
\text { ho martelo, pulverizador, } \\
\text { transportadores pesados, } \\
\text { máquina de carpintaria, pren- } \\
\text { sa, guilhotina, máquina de } \\
\text { borracha, peneira vibratório }\end{array}$ & 1,2 & 1,3 & 1,4 & 1,4 & 1,5 & 1,6 \\
\hline $\begin{array}{l}\text { Choque pesado: Triturador, } \\
\text { britador, moinho de bolas, } \\
\text { guindastes, extrusores, calan- } \\
\text { dra }\end{array}$ & 1,3 & 1,4 & 1,5 & 1,5 & 1,6 & 1,8 \\
\hline Máquina que pode afogar & 2,0 & 2,0 & 2,0 & 2,0 & 2,0 & 2,0 \\
\hline
\end{tabular}


Outro dado importante no início do projeto de seleção de uma correia, é escolher o tipo de seção da correia. Para tal, devem ser usados os gráficos da Figuras 9, 10 e 11, ingressando a potência de projeto, no eixo $x$ do gráfico; a rotação em rpm, no eixo $y$ do gráfico. Os gráficos apresentados a seguir são adaptações de [4].

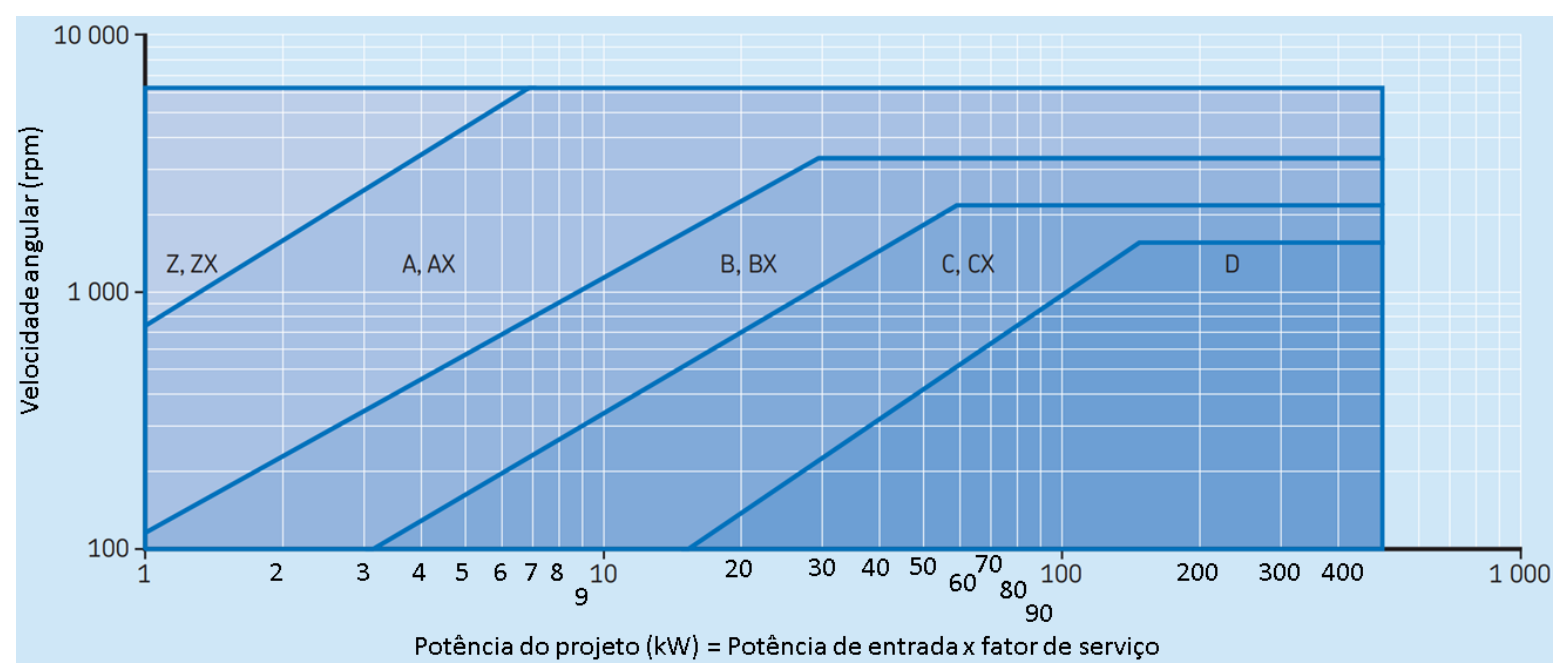

Figura 9: Gráfico para seleção de correia tipo Z, A, B, C e D

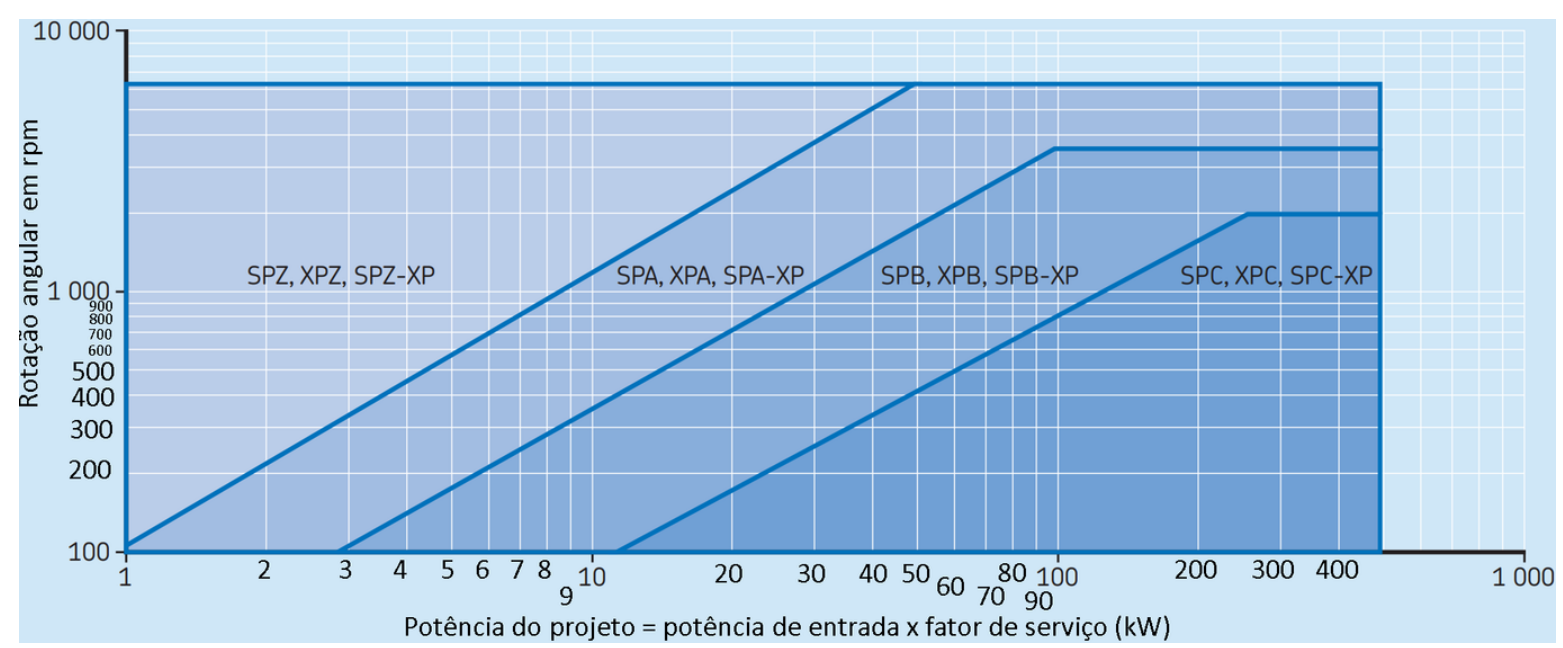

Figura 10: Gráfico para seleção de correia tipo SPZ, SPA, SPB e SPC 


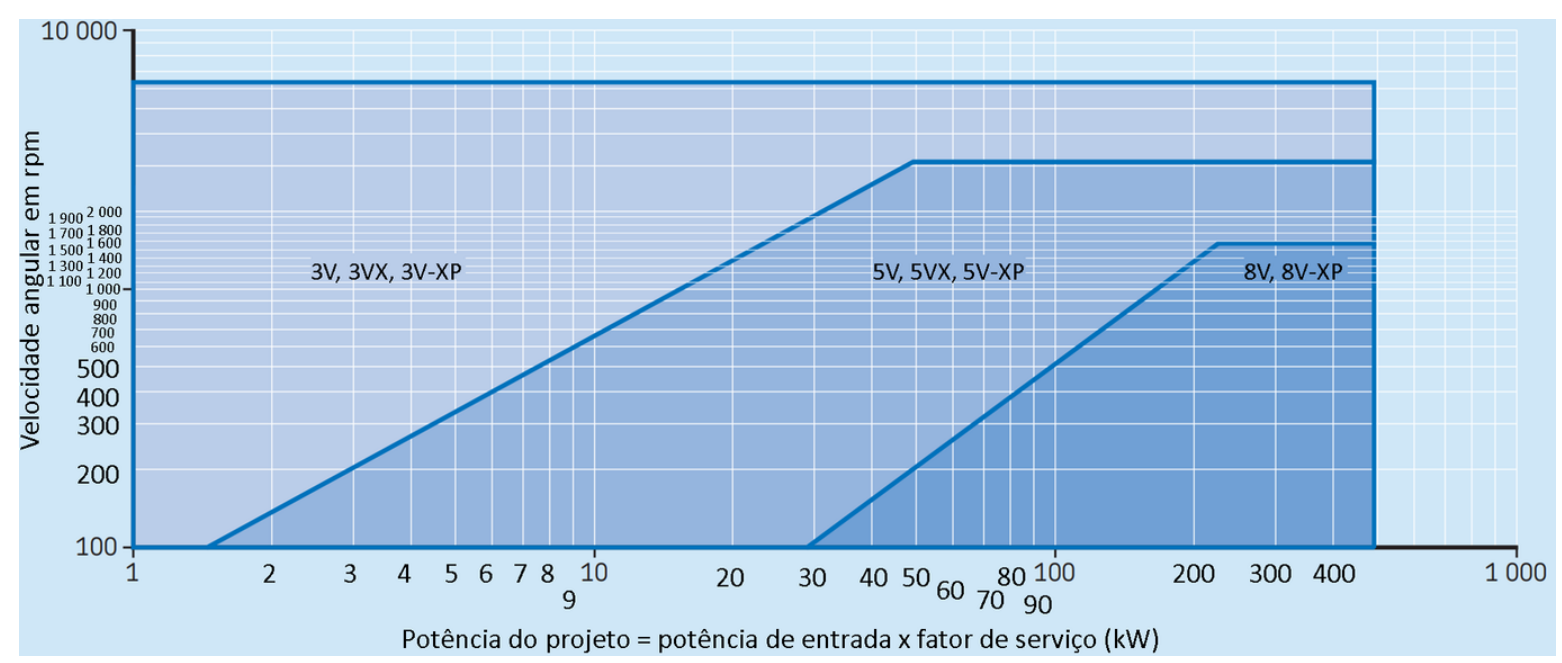

Figura 11: Gráfico para seleção de correia tipo 3V, $5 \mathrm{~V}$ e $8 \mathrm{~V}$

Tendo-se escolhido o tipo de seção de correia em V, podem ser determinados o diâmetros das polias, usando as equações 1 e 3 . Caso não seja fornecido nenhum dado sobre a velocidade linear, deve ser considerada a recomendação de [3], ou seja, $V=20 \mathrm{~m} / \mathrm{s}$. Assim, podem ser definidos os diâmetros preliminares das polias, que posteriormente devem ser ajustados segundo disponibilidade do fornecedor e/ou diâmetros de polias padronizadas.

Para encontrar a distância entre centros preliminar das polias, $C_{p}$, esta deve ser maior que o diâmetro de passo da maior polia, $D$, mas não deve passar o valor do produto da soma dos dois diâmetros diâmetros de passo, $D$ e $d$, multiplicada por 3, ou seja: $D<C_{p}<3 \cdot(D+d)$ [3].

Esse intervalo da distância de centro preliminar das polias, $C_{p}$, deve ser escolhido buscando conservar o espaço disponível para o sistema de transmissão. Em alguns casos esse tamanho é uma exigência de projeto, ou seja, é um dado de entrada, mas, que não deve estar fora da $C_{p}$ encontrada.

O comprimento preliminar total da correia, $L_{p}$, considerando os diâmetros de passo, pode ser obtido com a Equação 4 [3].

$$
L_{p}=2 C_{p}+1,57(D+d)+\frac{(D-d)^{2}}{4 C_{p}}
$$

O $L_{p}$ deve ser ajustado conforme disponibilidade do fabricante, que por sua vez segue normas específicas que padronizam e ajudam selecionar comprimento real $L$. 
A distância real entre centros de polias, $C$, pode ser encontrada com a Equação 5 [3].

$$
C=\frac{B+\sqrt{B^{2}-32 \cdot(D-d)^{2}}}{16}
$$

onde a constante $B=4 L-6,28 \cdot(D+d)$

Os cálculos do sistema de transmissão por correia em V consideram a potência para uma correia. Para saber qual é essa potência unitária, $P_{u}$, devem ser consultados catálogos de fabricantes que mostram esse valor. Normalmente, para encontrar a $P_{u}$ deve ser ingressado o diâmetro de passo da polia menor e cruzar com valores de rotação em rpm. Quando a potência unitária está abaixo da potência de projeto, $P_{d}$, deve ser considerado o uso de mais de uma correia, por esse motivo, deve ser acrescentado um acréscimo de potência, $P_{a}$, à potência unitária, $P_{u}$. Para encontrar esse acréscimo normalmente se ingressa o índice de velocidade, $i$, e é cruzado com a rotação da polia em rpm. Dessa forma, tem-se a potência básica, $P_{b}$, que é $P_{u}+P_{a}$. A seguir na Figura 12 é apresentada uma imagem com esses valores para uma correia tipo SPB e 5V e a Figura 13 para correia SPZ e 3V, que é uma adaptação de [4]. Para outros tipos de correias, devem ser consultados catálogos de fabricantes de correias.

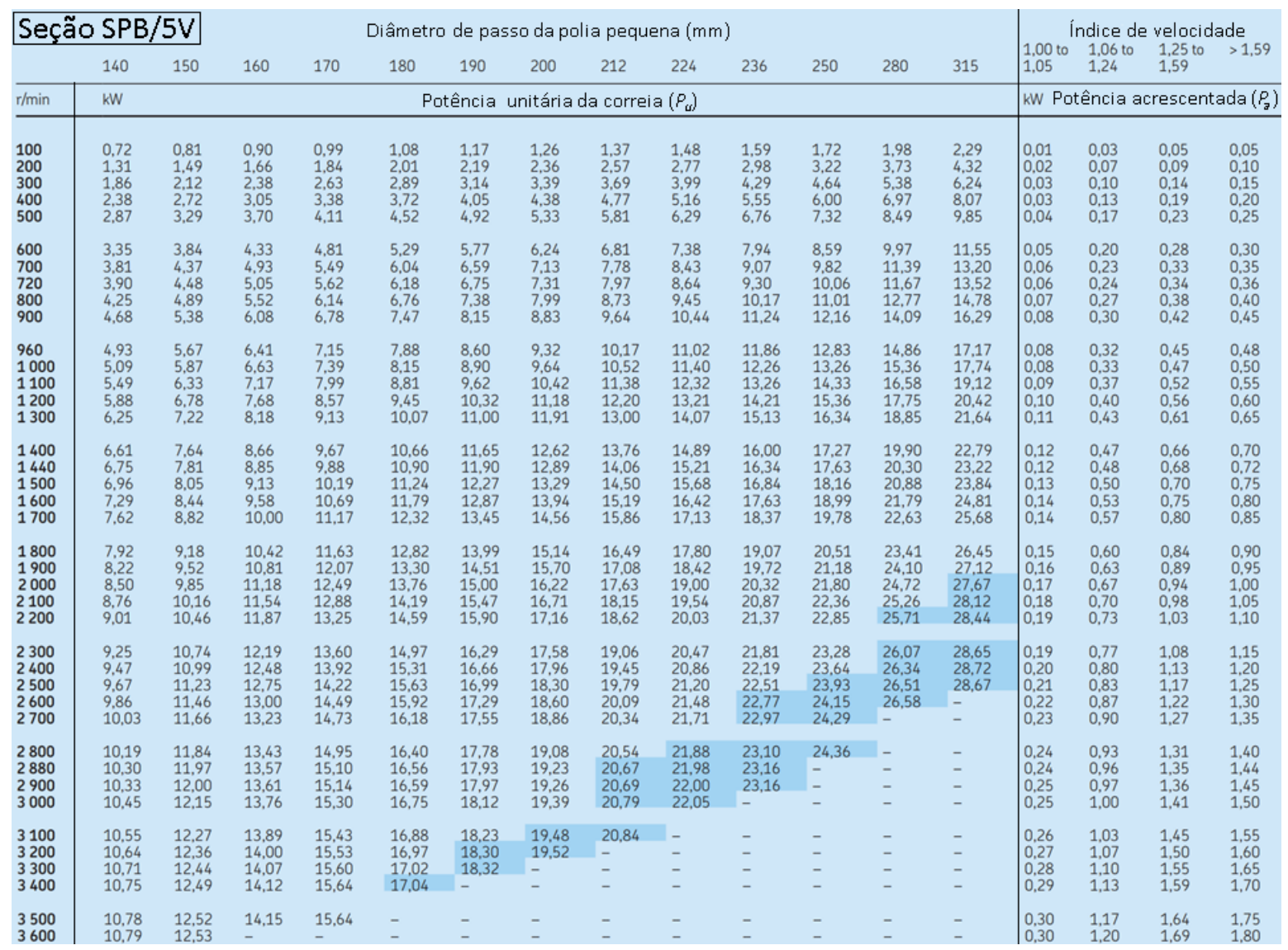

Figura 12: Potência unitária e de acréscimo para correias seção SPB e 5V 


\begin{tabular}{|c|c|c|c|c|c|c|c|c|c|c|c|c|c|c|c|c|}
\hline \multicolumn{3}{|c|}{ Seção SPZ/3V } & \multicolumn{10}{|c|}{ Rated power per belt for small pulley datum diameter [mm] } & \multicolumn{4}{|c|}{$\begin{array}{l}\text { Additional power per belt for } \\
\text { speed ratio }\end{array}$} \\
\hline & 67 & 71 & 75 & 80 & 85 & 90 & 95 & 100 & 112 & 125 & 132 & 140 & $\begin{array}{l}1,00 \text { to } \\
1,05\end{array}$ & $\begin{array}{l}1,06 \text { to } \\
1,24\end{array}$ & $\begin{array}{l}1,25 \text { to } \\
1,59\end{array}$ & $>1,59$ \\
\hline $\mathrm{r} / \mathrm{min}$ & $\mathrm{kW}$ & & & & & & & & & & & & $\mathrm{kW}$ & & & \\
\hline $\begin{array}{l}100 \\
500 \\
720 \\
800 \\
900\end{array}$ & $\begin{array}{l}0,11 \\
0,45 \\
0,61 \\
0,66 \\
0,73\end{array}$ & $\begin{array}{l}0,13 \\
0,51 \\
0,69 \\
0,76 \\
0,83\end{array}$ & $\begin{array}{l}0,14 \\
0,57 \\
0,78 \\
0,85 \\
0,94\end{array}$ & $\begin{array}{l}0,16 \\
0,65 \\
0,89 \\
0,97 \\
1,07\end{array}$ & $\begin{array}{l}0,17 \\
0,72 \\
0,99 \\
1,09 \\
1,20\end{array}$ & $\begin{array}{l}0,19 \\
0,80 \\
1,10 \\
1,20 \\
1,33\end{array}$ & $\begin{array}{l}0,21 \\
0,87 \\
1,20 \\
1,32 \\
1,46\end{array}$ & $\begin{array}{l}0,22 \\
0,95 \\
1,31 \\
1,43 \\
1,59\end{array}$ & $\begin{array}{l}0,26 \\
1,13 \\
1,56 \\
1,71 \\
1,89\end{array}$ & $\begin{array}{l}0,31 \\
1,32 \\
1,82 \\
2,00 \\
2,22\end{array}$ & $\begin{array}{l}0,33 \\
1,42 \\
1,97 \\
2,16 \\
2,40\end{array}$ & $\begin{array}{l}0,36 \\
1,54 \\
2,13 \\
2,34 \\
2,60\end{array}$ & $\begin{array}{l}\overline{0}, 01 \\
0,01 \\
0,01 \\
0,01\end{array}$ & $\begin{array}{l}0,01 \\
0,03 \\
0,05 \\
0,05 \\
0,06\end{array}$ & $\begin{array}{l}0,01 \\
0,06 \\
0,08 \\
0,09 \\
0,10\end{array}$ & $\begin{array}{l}0,01 \\
0,06 \\
0,09 \\
0,10 \\
0,11\end{array}$ \\
\hline $\begin{array}{l}960 \\
1000 \\
1100 \\
1200 \\
1300\end{array}$ & $\begin{array}{l}0,77 \\
0,79 \\
0,86 \\
0,92 \\
0,98\end{array}$ & $\begin{array}{l}0,88 \\
0,91 \\
0,98 \\
1,06 \\
1,13\end{array}$ & $\begin{array}{l}0,99 \\
1,03 \\
1,11 \\
1,19 \\
1,28\end{array}$ & $\begin{array}{l}1,13 \\
1,17 \\
1,27 \\
1,36 \\
1,46\end{array}$ & $\begin{array}{l}1,27 \\
1,31 \\
1,42 \\
1,53 \\
1,64\end{array}$ & $\begin{array}{l}1,41 \\
1,46 \\
1,58 \\
1,70 \\
1,82\end{array}$ & $\begin{array}{l}1,54 \\
1,60 \\
1,74 \\
1,87 \\
2,00\end{array}$ & $\begin{array}{l}1,68 \\
1,74 \\
1,89 \\
2,04 \\
2,18\end{array}$ & $\begin{array}{l}2,00 \\
2,08 \\
2,26 \\
2,43 \\
2,61\end{array}$ & $\begin{array}{l}2,35 \\
2,44 \\
2,65 \\
2,86 \\
3,06\end{array}$ & $\begin{array}{l}2,54 \\
2,63 \\
2,86 \\
3,08 \\
3,30\end{array}$ & $\begin{array}{l}2,75 \\
2,85 \\
3,10 \\
3,34 \\
3,58\end{array}$ & $\begin{array}{l}0,02 \\
0,02 \\
0,02 \\
0,02 \\
0,02\end{array}$ & $\begin{array}{l}0,07 \\
0,07 \\
0,08 \\
0,08 \\
0,09\end{array}$ & $\begin{array}{l}0,11 \\
0,11 \\
0,12 \\
0,13 \\
0,14\end{array}$ & $\begin{array}{l}0,12 \\
0,13 \\
0,14 \\
0,15 \\
0,17\end{array}$ \\
\hline $\begin{array}{l}1400 \\
1440 \\
1500 \\
1600 \\
1700\end{array}$ & $\begin{array}{l}1,04 \\
1,06 \\
1,10 \\
1,15 \\
1,21\end{array}$ & $\begin{array}{l}1,20 \\
1,22 \\
1,27 \\
1,33 \\
1,40\end{array}$ & $\begin{array}{l}1,35 \\
1,39 \\
1,43 \\
1,51 \\
1,59\end{array}$ & $\begin{array}{l}1,55 \\
1,59 \\
1,64 \\
1,73 \\
1,82\end{array}$ & $\begin{array}{l}1,75 \\
1,79 \\
1,85 \\
1,95 \\
2,05\end{array}$ & $\begin{array}{l}1,94 \\
1,99 \\
2,05 \\
2,17 \\
2,28\end{array}$ & $\begin{array}{l}2,13 \\
2,18 \\
2,26 \\
2,38 \\
2,51\end{array}$ & $\begin{array}{l}2,32 \\
2,38 \\
2,46 \\
2,60 \\
2,73\end{array}$ & $\begin{array}{l}2,78 \\
2,84 \\
2,94 \\
3,11 \\
3,27\end{array}$ & $\begin{array}{l}3,26 \\
3,34 \\
3,46 \\
3,65 \\
3,84\end{array}$ & $\begin{array}{l}3,52 \\
3,61 \\
3,73 \\
3,94 \\
4,15\end{array}$ & $\begin{array}{l}3,81 \\
3,90 \\
4,04 \\
4,27 \\
4,49\end{array}$ & $\begin{array}{l}0,02 \\
0,02 \\
0,02 \\
0,03 \\
0,03\end{array}$ & $\begin{array}{l}0,10 \\
0,10 \\
0,10 \\
0,11 \\
0,12\end{array}$ & $\begin{array}{l}0,15 \\
0,16 \\
0,17 \\
0,18 \\
0,19\end{array}$ & $\begin{array}{l}0,18 \\
0,18 \\
0,19 \\
0,20 \\
0,22\end{array}$ \\
\hline $\begin{array}{l}1800 \\
1900 \\
2000 \\
2100 \\
2200\end{array}$ & $\begin{array}{l}1,26 \\
1,32 \\
1,37 \\
1,42 \\
1,47\end{array}$ & $\begin{array}{l}1,46 \\
1,52 \\
1,59 \\
1,65 \\
1,71\end{array}$ & $\begin{array}{l}1,66 \\
1,73 \\
1,80 \\
1,87 \\
1,94\end{array}$ & $\begin{array}{l}1,90 \\
1,99 \\
2,07 \\
2,15 \\
2,23\end{array}$ & $\begin{array}{l}2,15 \\
2,24 \\
2,34 \\
2,43 \\
2,52\end{array}$ & $\begin{array}{l}2,39 \\
2,50 \\
2,60 \\
2,71 \\
2,81\end{array}$ & $\begin{array}{l}2,63 \\
2,75 \\
2,87 \\
2,98 \\
3,09\end{array}$ & $\begin{array}{l}2,87 \\
3,00 \\
3,13 \\
3,25 \\
3,38\end{array}$ & $\begin{array}{l}3,43 \\
3,59 \\
3,74 \\
3,89 \\
4,04\end{array}$ & $\begin{array}{l}4,03 \\
4,21 \\
4,39 \\
4,57 \\
4,74\end{array}$ & $\begin{array}{l}4,35 \\
4,55 \\
4,74 \\
4,93 \\
5,11\end{array}$ & $\begin{array}{l}4,71 \\
4,92 \\
5,13 \\
5,33 \\
5,53\end{array}$ & $\begin{array}{l}0,03 \\
0,03 \\
0,03 \\
0,03 \\
0,03\end{array}$ & $\begin{array}{l}0,12 \\
0,13 \\
0,14 \\
0,14 \\
0,15\end{array}$ & $\begin{array}{l}0,20 \\
0,21 \\
0,22 \\
0,23 \\
0,24\end{array}$ & $\begin{array}{l}0,23 \\
0,24 \\
0,26 \\
0,27 \\
0,28\end{array}$ \\
\hline $\begin{array}{l}2300 \\
2400 \\
2500 \\
2600 \\
2700\end{array}$ & $\begin{array}{l}1,52 \\
1,57 \\
1,61 \\
1,66 \\
1,70\end{array}$ & $\begin{array}{l}1,77 \\
1,82 \\
1,88 \\
1,93 \\
1,99\end{array}$ & $\begin{array}{l}2,01 \\
2,08 \\
2,14 \\
2,20 \\
2,27\end{array}$ & $\begin{array}{l}2,31 \\
2,39 \\
2,47 \\
2,54 \\
2,61\end{array}$ & $\begin{array}{l}2,61 \\
2,70 \\
2,79 \\
2,87 \\
2,96\end{array}$ & $\begin{array}{l}2,91 \\
3,01 \\
3,11 \\
3,20 \\
3,30\end{array}$ & $\begin{array}{l}3,21 \\
3,31 \\
3,42 \\
3,53 \\
3,63\end{array}$ & $\begin{array}{l}3,50 \\
3,62 \\
3,73 \\
3,85 \\
3,96\end{array}$ & $\begin{array}{l}4,19 \\
4,33 \\
4,47 \\
4,60 \\
4,74\end{array}$ & $\begin{array}{l}4,91 \\
5,08 \\
5,24 \\
5,40 \\
5,55\end{array}$ & $\begin{array}{l}5,30 \\
5,47 \\
5,65 \\
5,81 \\
5,98\end{array}$ & $\begin{array}{l}5,73 \\
5,92 \\
6,10 \\
6,28 \\
6,45\end{array}$ & $\begin{array}{l}0,04 \\
0,04 \\
0,04 \\
0,04 \\
0,04\end{array}$ & $\begin{array}{l}0,16 \\
0,16 \\
0,17 \\
0,18 \\
0,18\end{array}$ & $\begin{array}{l}0,25 \\
0,27 \\
0,28 \\
0,29 \\
0,30\end{array}$ & $\begin{array}{l}0,29 \\
0,31 \\
0,32 \\
0,33 \\
0,34\end{array}$ \\
\hline $\begin{array}{l}2800 \\
2880 \\
2900 \\
3000 \\
3100\end{array}$ & $\begin{array}{l}1,75 \\
1,78 \\
1,79 \\
1,83 \\
1,87\end{array}$ & $\begin{array}{l}2,04 \\
2,08 \\
2,09 \\
2,14 \\
2,19\end{array}$ & $\begin{array}{l}2,33 \\
2,38 \\
2,39 \\
2,45 \\
2,51\end{array}$ & $\begin{array}{l}2,69 \\
2,74 \\
2,76 \\
2,83 \\
2,89\end{array}$ & $\begin{array}{l}3,04 \\
3,10 \\
3,12 \\
3,20 \\
3,27\end{array}$ & $\begin{array}{l}3,39 \\
3,46 \\
3,48 \\
3,57 \\
3,65\end{array}$ & $\begin{array}{l}3,73 \\
3,81 \\
3,83 \\
3,93 \\
4,02\end{array}$ & $\begin{array}{l}4,07 \\
4,16 \\
4,18 \\
4,29 \\
4,39\end{array}$ & $\begin{array}{l}4,87 \\
4,97 \\
5,00 \\
5,12 \\
5,24\end{array}$ & $\begin{array}{l}5,70 \\
5,82 \\
5,85 \\
5,99 \\
6,13\end{array}$ & $\begin{array}{l}6,14 \\
6,26 \\
6,29 \\
6,45 \\
6,59\end{array}$ & $\begin{array}{l}6,62 \\
6,76 \\
6,79 \\
6,95 \\
7,10\end{array}$ & $\begin{array}{l}0,04 \\
0,05 \\
0,05 \\
0,05 \\
0,05\end{array}$ & $\begin{array}{l}0,19 \\
0,20 \\
0,20 \\
0,21 \\
0,21\end{array}$ & $\begin{array}{l}0,31 \\
0,32 \\
0,32 \\
0,33 \\
0,34\end{array}$ & $\begin{array}{l}0,36 \\
0,37 \\
0,37 \\
0,38 \\
0,40\end{array}$ \\
\hline $\begin{array}{l}3200 \\
3300 \\
3400 \\
3500 \\
3600\end{array}$ & $\begin{array}{l}1,91 \\
1,95 \\
1,99 \\
2,03 \\
2,06\end{array}$ & $\begin{array}{l}2,24 \\
2,29 \\
2,33 \\
2,38 \\
2,42\end{array}$ & $\begin{array}{l}2,56 \\
2,62 \\
2,67 \\
2,72 \\
2,77\end{array}$ & $\begin{array}{l}2,96 \\
3,02 \\
3,09 \\
3,15 \\
3,21\end{array}$ & $\begin{array}{l}3,35 \\
3,42 \\
3,50 \\
3,57 \\
3,63\end{array}$ & $\begin{array}{l}3,74 \\
3,82 \\
3,90 \\
3,98 \\
4,05\end{array}$ & $\begin{array}{l}4,12 \\
4,21 \\
4,30 \\
4,38 \\
4,47\end{array}$ & $\begin{array}{l}4,49 \\
4,59 \\
4,68 \\
4,78 \\
4,87\end{array}$ & $\begin{array}{l}5,36 \\
5,48 \\
5,59 \\
5,70 \\
5,80\end{array}$ & $\begin{array}{l}6,27 \\
6,40 \\
6,52 \\
6,64 \\
6,76\end{array}$ & $\begin{array}{l}6,73 \\
6,87 \\
7,00 \\
7,13 \\
7,25\end{array}$ & $\begin{array}{l}7,25 \\
7,39 \\
7,53 \\
7,66 \\
7,78\end{array}$ & $\begin{array}{l}0,05 \\
0,05 \\
0,05 \\
0,06 \\
0,06\end{array}$ & $\begin{array}{l}0,22 \\
0,23 \\
0,23 \\
0,24 \\
0,25\end{array}$ & $\begin{array}{l}0,35 \\
0,36 \\
0,38 \\
0,39 \\
0,40\end{array}$ & $\begin{array}{l}0,41 \\
0,42 \\
0,43 \\
0,45 \\
0,46\end{array}$ \\
\hline $\begin{array}{l}3700 \\
3800 \\
3900 \\
4000 \\
4200\end{array}$ & $\begin{array}{l}2,10 \\
2,13 \\
2,17 \\
2,20 \\
2,26\end{array}$ & $\begin{array}{l}2,46 \\
2,50 \\
2,55 \\
2,58 \\
2,66\end{array}$ & $\begin{array}{l}2,82 \\
2,87 \\
2,92 \\
2,97 \\
3,05\end{array}$ & $\begin{array}{l}3,27 \\
3,32 \\
3,38 \\
3,43 \\
3,54\end{array}$ & $\begin{array}{l}3,70 \\
3,77 \\
3,83 \\
3,89 \\
4,01\end{array}$ & $\begin{array}{l}4,13 \\
4,20 \\
4,27 \\
4,34 \\
4,47\end{array}$ & $\begin{array}{l}4,55 \\
4,63 \\
4,70 \\
4,78 \\
4,92\end{array}$ & $\begin{array}{l}4,96 \\
5,04 \\
5,13 \\
5,21 \\
5,36\end{array}$ & $\begin{array}{l}5,90 \\
6,00 \\
6,10 \\
6,19 \\
6,36\end{array}$ & $\begin{array}{l}6,87 \\
6,98 \\
7,08 \\
7,18 \\
7,36\end{array}$ & $\begin{array}{l}7,36 \\
7,47 \\
7,58 \\
7,67 \\
7,85\end{array}$ & $\begin{array}{l}7,90 \\
8,01 \\
8,11 \\
8,21 \\
8,39\end{array}$ & $\begin{array}{l}0,06 \\
0,06 \\
0,06 \\
0,06 \\
0,07\end{array}$ & $\begin{array}{l}0,25 \\
0,26 \\
0,27 \\
0,27 \\
0,29\end{array}$ & $\begin{array}{l}0,41 \\
0,42 \\
0,43 \\
0,44 \\
0,46\end{array}$ & $\begin{array}{l}0,47 \\
0,48 \\
0,50 \\
0,51 \\
0,54\end{array}$ \\
\hline $\begin{array}{l}4400 \\
4600 \\
4800 \\
5000 \\
5200\end{array}$ & $\begin{array}{l}2,31 \\
2,37 \\
2,41 \\
2,46 \\
2,49\end{array}$ & $\begin{array}{l}2,73 \\
2,79 \\
2,85 \\
2,91 \\
2,96\end{array}$ & $\begin{array}{l}3,14 \\
3,21 \\
3,28 \\
3,35 \\
3,41\end{array}$ & $\begin{array}{l}3,63 \\
3,72 \\
3,81 \\
3,88 \\
3,95\end{array}$ & $\begin{array}{l}4,12 \\
4,22 \\
4,32 \\
4,40 \\
4,48\end{array}$ & $\begin{array}{l}4,59 \\
4,70 \\
4,81 \\
4,90 \\
4,99\end{array}$ & $\begin{array}{l}5,05 \\
5,17 \\
5,29 \\
5,39 \\
5,47\end{array}$ & $\begin{array}{l}5,50 \\
5,63 \\
5,75 \\
5,85 \\
5,94\end{array}$ & $\begin{array}{l}6,51 \\
6,65 \\
6,78 \\
6,88 \\
6,97\end{array}$ & $\begin{array}{l}7,52 \\
7,65 \\
7,77 \\
7,86 \\
7,93\end{array}$ & $\begin{array}{l}8,01 \\
8,14 \\
8,25 \\
8,32 \\
8,38\end{array}$ & $\begin{array}{l}8,53 \\
8,65 \\
8,74 \\
8,80 \\
8,82\end{array}$ & $\begin{array}{l}0,07 \\
0,07 \\
0,08 \\
0,08 \\
0,08\end{array}$ & $\begin{array}{l}0,30 \\
0,32 \\
0,33 \\
0,34 \\
0,36\end{array}$ & $\begin{array}{l}0,49 \\
0,51 \\
0,53 \\
0,55 \\
0,57\end{array}$ & $\begin{array}{l}0,56 \\
0,59 \\
0,61 \\
0,64 \\
0,66\end{array}$ \\
\hline $\begin{array}{l}5400 \\
5600 \\
5800 \\
6000\end{array}$ & $\begin{array}{l}2,53 \\
2,56 \\
2,58 \\
2,60\end{array}$ & $\begin{array}{l}3,00 \\
3,04 \\
3,07 \\
3,10\end{array}$ & $\begin{array}{l}3,46 \\
3,50 \\
3,54 \\
3,58\end{array}$ & $\begin{array}{l}4,01 \\
4,07 \\
4,11 \\
4,15\end{array}$ & $\begin{array}{l}4,55 \\
4,61 \\
4,66 \\
4,70\end{array}$ & $\begin{array}{l}5,06 \\
5,13 \\
5,18 \\
5,22\end{array}$ & $\begin{array}{l}5,55 \\
5,62 \\
5,67 \\
5,71\end{array}$ & $\begin{array}{l}6,02 \\
6,08 \\
6,14 \\
6,17\end{array}$ & $\begin{array}{l}7,04 \\
7,09 \\
7,12 \\
7,14\end{array}$ & $\begin{array}{l}7,97 \\
7,99 \\
- \\
-\end{array}$ & $\begin{array}{l}8,40 \\
- \\
-\end{array}$ & $\begin{array}{l}- \\
\overline{-} \\
-\end{array}$ & $\begin{array}{l}0,09 \\
0,09 \\
0,09 \\
0,09\end{array}$ & $\begin{array}{l}0,37 \\
0,38 \\
0,40 \\
0,41\end{array}$ & $\begin{array}{l}0,60 \\
0,62 \\
0,64 \\
0,66\end{array}$ & $\begin{array}{l}0,69 \\
0,71 \\
0,74 \\
0,77\end{array}$ \\
\hline $\begin{array}{l}6200 \\
6400 \\
6600 \\
6800\end{array}$ & $\begin{array}{l}2,62 \\
2,62 \\
2,63 \\
-\end{array}$ & $\begin{array}{l}3,12 \\
3,13 \\
3,14 \\
3,14\end{array}$ & $\begin{array}{l}3,60 \\
3,62 \\
3,64 \\
3,64\end{array}$ & $\begin{array}{l}4,18 \\
4,21 \\
4,22 \\
4,23\end{array}$ & $\begin{array}{l}4,73 \\
4,76 \\
4,77 \\
4,77\end{array}$ & $\begin{array}{l}5,25 \\
5,27 \\
5,28 \\
-\end{array}$ & $\begin{array}{l}5,74 \\
5,76 \\
5,76 \\
-\end{array}$ & $\begin{array}{l}6,19 \\
6,20 \\
- \\
-\end{array}$ & $\begin{array}{l}- \\
\overline{-} \\
-\end{array}$ & $\begin{array}{l}- \\
- \\
-\end{array}$ & $\begin{array}{l}\overline{-} \\
\overline{-}\end{array}$ & $\begin{array}{l}\overline{-} \\
\overline{-}\end{array}$ & $\begin{array}{l}0,10 \\
0,10 \\
0,10 \\
0,11\end{array}$ & $\begin{array}{l}0,42 \\
0,44 \\
0,45 \\
0,47\end{array}$ & $\begin{array}{l}0,69 \\
0,71 \\
0,73 \\
0,75\end{array}$ & $\begin{array}{l}0,79 \\
0,82 \\
0,84 \\
0,87\end{array}$ \\
\hline
\end{tabular}

Figura 13: Potência unitária e de acréscimo para correias seção SPZ e 3V

O ângulo de contato para a polia motriz e movida, pode ser encontrado com o uso da Equação 6 e 7, respectivamente [3].

$$
\begin{aligned}
& \theta_{d}=180-2 \cdot \operatorname{sen}^{-1} \cdot \frac{D-d}{2 C} \\
& \theta_{D}=180+2 \cdot \operatorname{sen}^{-1} \cdot \frac{D-d}{2 C}
\end{aligned}
$$

Quando há diferença de diâmetros nas polias, a de menor diâmetro sempre terá um ângulo de contato inferior a $180^{\circ}$. Provocando uma redução na potência efetiva. Nesse sentido, deve ser considerado que o ângulo de envolvimento da polia menor não seja inferios a $120^{\circ}$ [3]. 
Tendo encontrado o ângulo de envolvimento, $\theta_{d}$, (normalmente apenas para a polia menor), deve ser encontrado a fator de correção do ângulo de envolvimento, $C_{\theta}$, usando o gráfico da Figura 14 para posteriormente corrigir a potência básica, $P_{b}$ [3].

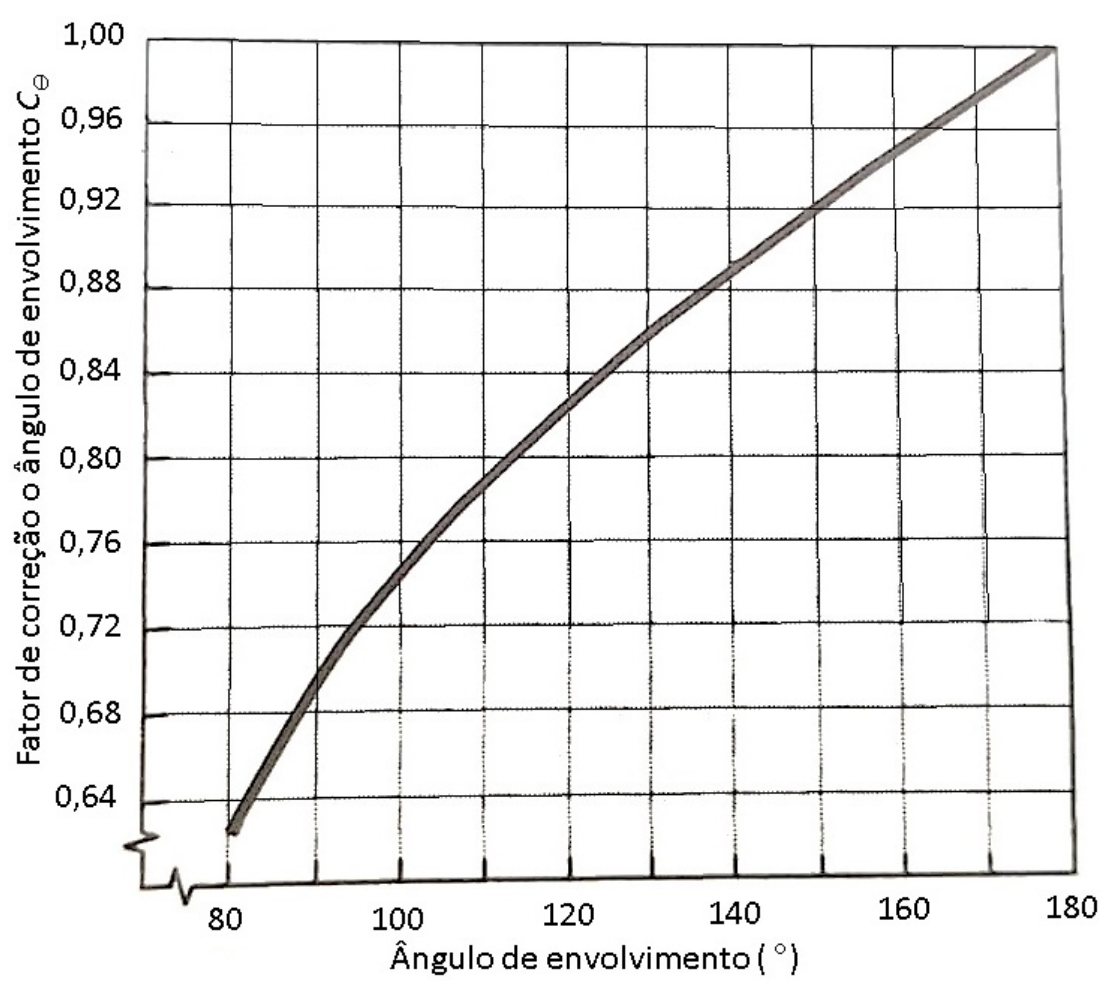

Figura 14: Fator de correção do ângulo de envolvimento

Também, com o comprimento da correia já selecionada, $L$, é corrigida a potência básica, $P_{b}$, usando a tabela da Figura 15, para encontrar o fator de correção do comprimento da correia, $C_{L}$, [4]. 


\begin{tabular}{|c|c|c|c|c|c|c|c|c|c|c|}
\hline 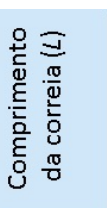 & $\mid \begin{array}{l}\text { SPZ } \\
\text { SPZ-XP } \\
\text { XPZ } \\
3 \mathrm{~V} \\
3 \mathrm{~V}-X P \\
3 \mathrm{VX}\end{array}$ & $\begin{array}{l}\text { SPA } \\
\text { SPA-XP } \\
\text { XPA }\end{array}$ & $\begin{array}{l}\text { SPB } \\
\text { SPB-XP } \\
\text { XPB } \\
5 V \\
5 V-X P \\
5 V X\end{array}$ & $\begin{array}{l}\text { SPC } \\
\text { SPC-XP } \\
\text { XPC }\end{array}$ & $\begin{array}{l}8 \mathrm{~V} \\
8 \mathrm{~V}-\mathrm{XP}\end{array}$ & $\begin{array}{l}Z \\
Z X\end{array}$ & $\begin{array}{l}A \\
A X\end{array}$ & $\begin{array}{l}\mathrm{B} \\
\mathrm{BX}\end{array}$ & $\begin{array}{l}c \\
c x\end{array}$ & D \\
\hline $\mathrm{mm}$ & \multicolumn{10}{|c|}{ Fator de correção do comprimento da correia $C_{\mathrm{L}}$} \\
\hline $\begin{array}{l}400 \\
475 \\
530\end{array}$ & $\begin{array}{l}0,50 \\
0,65 \\
0,74\end{array}$ & & & & & $\begin{array}{l}0,87 \\
0,90 \\
0,93\end{array}$ & $\begin{array}{l}0,68 \\
0,74 \\
0,78\end{array}$ & $\begin{array}{l}0,64 \\
0,70\end{array}$ & & \\
\hline $\begin{array}{l}630 \\
710 \\
900\end{array}$ & $\begin{array}{l}0,82 \\
0,84 \\
0,88\end{array}$ & $\begin{array}{l}0,77 \\
0,79 \\
0,83\end{array}$ & 0,76 & & & $\begin{array}{l}0,96 \\
0,99 \\
1,05\end{array}$ & $\begin{array}{l}0,81 \\
0,83 \\
0,87\end{array}$ & $\begin{array}{l}0,76 \\
0,78 \\
0,82\end{array}$ & 0,73 & \\
\hline $\begin{array}{l}1000 \\
1120 \\
1250\end{array}$ & $\begin{array}{l}0,90 \\
0,93 \\
0,95\end{array}$ & $\begin{array}{l}0,85 \\
0,87 \\
0,89\end{array}$ & $\begin{array}{l}0,78 \\
0,80 \\
0,82\end{array}$ & & & $\begin{array}{l}1,06 \\
1,08 \\
1,11\end{array}$ & $\begin{array}{l}0,89 \\
0,91 \\
0,93\end{array}$ & $\begin{array}{l}0,84 \\
0,86 \\
0,88\end{array}$ & $\begin{array}{l}0,76 \\
0,78 \\
0,80\end{array}$ & \\
\hline $\begin{array}{l}1400 \\
1600 \\
1800\end{array}$ & $\begin{array}{l}0,96 \\
1,00 \\
1,01\end{array}$ & $\begin{array}{l}0,91 \\
0,93 \\
0,95\end{array}$ & $\begin{array}{l}0,84 \\
0,86 \\
0,88\end{array}$ & $\begin{array}{l}0,70 \\
0,74 \\
0,77\end{array}$ & & $\begin{array}{l}1,14 \\
1,17 \\
1,22\end{array}$ & $\begin{array}{l}0,96 \\
0,99 \\
1,01\end{array}$ & $\begin{array}{l}0,90 \\
0,93 \\
0,95\end{array}$ & $\begin{array}{l}0,82 \\
0,84 \\
0,86\end{array}$ & \\
\hline $\begin{array}{l}2000 \\
2240 \\
2500\end{array}$ & $\begin{array}{l}1,02 \\
1,05 \\
1,07\end{array}$ & $\begin{array}{l}0,96 \\
0,98 \\
1,00\end{array}$ & $\begin{array}{l}0,90 \\
0,92 \\
0,94\end{array}$ & $\begin{array}{l}0,80 \\
0,83 \\
0,86\end{array}$ & $\begin{array}{l}0,78 \\
0,80 \\
0,80\end{array}$ & $\begin{array}{l}1,25 \\
1,28 \\
1,29\end{array}$ & $\begin{array}{l}1,03 \\
1,06 \\
1,09\end{array}$ & $\begin{array}{l}0,98 \\
1,00 \\
1,03\end{array}$ & $\begin{array}{l}0,88 \\
0,91 \\
0,93\end{array}$ & $\begin{array}{l}0,78 \\
0,80 \\
0,82\end{array}$ \\
\hline $\begin{array}{l}2800 \\
3150 \\
3550\end{array}$ & $\begin{array}{l}1,09 \\
1,11 \\
1,13\end{array}$ & $\begin{array}{l}1,02 \\
1,04 \\
1,06\end{array}$ & $\begin{array}{l}0,96 \\
0,98 \\
1,00\end{array}$ & $\begin{array}{l}0,88 \\
0,90 \\
0,92\end{array}$ & $\begin{array}{l}0,82 \\
0,84 \\
0,86\end{array}$ & 1,29 & $\begin{array}{l}1,11 \\
1,13 \\
1,15\end{array}$ & $\begin{array}{l}1,05 \\
1,07 \\
1,09\end{array}$ & $\begin{array}{l}0,95 \\
0,97 \\
0,99\end{array}$ & $\begin{array}{l}0,84 \\
0,86 \\
0,88\end{array}$ \\
\hline $\begin{array}{l}4000 \\
4500 \\
5000\end{array}$ & $\begin{array}{l}1,13 \\
1,13\end{array}$ & $\begin{array}{l}1,08 \\
1,09 \\
1,09\end{array}$ & $\begin{array}{l}1,02 \\
1,04 \\
1,06\end{array}$ & $\begin{array}{l}0,94 \\
0,96 \\
0,98\end{array}$ & $\begin{array}{l}0,89 \\
0,91 \\
0,94\end{array}$ & & $\begin{array}{l}1,17 \\
1,17 \\
1,17\end{array}$ & $\begin{array}{l}1,13 \\
1,15 \\
1,18\end{array}$ & $\begin{array}{l}1,02 \\
1,04 \\
1,07\end{array}$ & $\begin{array}{l}0,91 \\
0,93 \\
0,96\end{array}$ \\
\hline $\begin{array}{l}5600 \\
6300 \\
7100\end{array}$ & & 1,09 & $\begin{array}{l}1,08 \\
1,10 \\
1,12\end{array}$ & $\begin{array}{l}1,00 \\
1,02 \\
1,04\end{array}$ & $\begin{array}{l}0,96 \\
0,99 \\
1,02\end{array}$ & & $\begin{array}{l}1,17 \\
1,17\end{array}$ & $\begin{array}{l}1,20 \\
1,23 \\
1,23\end{array}$ & $\begin{array}{l}1,09 \\
1,12 \\
1,15\end{array}$ & $\begin{array}{l}0,98 \\
1,01 \\
1,04\end{array}$ \\
\hline $\begin{array}{l}8000 \\
9000 \\
10000\end{array}$ & & & $\begin{array}{l}1,14 \\
1,14 \\
1,14\end{array}$ & $\begin{array}{l}1,06 \\
1,08 \\
1,10\end{array}$ & $\begin{array}{l}1,04 \\
1,07 \\
1,09\end{array}$ & & & $\begin{array}{l}1,23 \\
1,23 \\
1,23\end{array}$ & $\begin{array}{l}1,18 \\
1,21 \\
1,23\end{array}$ & $\begin{array}{l}1,06 \\
1,09 \\
1,11\end{array}$ \\
\hline $\begin{array}{l}11200 \\
12500\end{array}$ & & & & $\begin{array}{l}1,12 \\
1,14\end{array}$ & $\begin{array}{l}1,12 \\
1,15\end{array}$ & & & & $\begin{array}{l}1,23 \\
1,23\end{array}$ & $\begin{array}{l}1,14 \\
1,17\end{array}$ \\
\hline
\end{tabular}

Figura 15: Fator de correção de comprimento $C_{L}$

Finalmente, se a distância de vão, $S$, for grande demais, pode chicotear e gerar vibração desnecessária ao sistema de transmissão. Essa distância pode ser encontrada com a Equação 8 [3].

$$
S=\sqrt{C^{2}-\frac{(D-d)^{2}}{2}}
$$

\section{Estudo de caso correias perfil em V}

Para acompanhar o procedimento de dimensionamento e seleção de uma correia de transmissão perfil em V, recomendadas neste trabalho, é adaptado um exemplo de [4]. 
Precisa-se projetar o sistema de transmissão, usando correias em V, para um ventilador que é acionado por um motor elétrico, com partida pesada. Para projetar a polia motriz, no eixo do motor elétrico há uma potência de saída de $45 \mathrm{~kW}$ com rotação de $1440 \mathrm{rpm}$. A polia movida do ventilador deve ter uma rotação próxima de $600 \mathrm{rpm}$. O serviço desse equipamento é de 24 h/dia; distância desejada entre centros deve ser menor ou igual a $900 \mathrm{~mm}$.

Da Tabela 1 encontra-se o fator de serviço da correia ingressando o tempo de trabalho e tipo de máquina acionada, $f=1,4$. Esse fator de serviço é multiplicado com a potência de $45 \mathrm{~kW}$, obtendo uma nova potência do projeto, $P_{p}=63 \mathrm{~kW}$.

Usando as figuras 9, 10 e 11, e ingressando $P_{p}=63 \mathrm{~kW}$, mais a rotação $\omega=1440 \mathrm{rpm}$, pode ser escolhida a seção da correia em V adequada, podendo ser: SPB, C ou 5V. Neste exemplo, será feito o detalhamento de uma correia em V seção SPB.

Com a Equação 2 pode ser encontrado o torque na polia motriz, $T=298,4 \mathrm{~N} \cdot \mathrm{m}$. Tendo as rotações do motor e a rotação desejada para o ventilador, usando a Equação 3, pode ser determinado o índice de velocidade preliminar, $i_{p}=2,4$.

Normalmente não há uma exigência de velocidade linear, que o sistema deve atender, sendo assim, de acordo com a recomendação de [3], usa-se a velocidade linear nominal para uma correia em $\mathrm{V}$ que é $V \approx 20 \frac{\mathrm{m}}{\mathrm{s}}$. Assim, usando a Equação 1 pode ser encontrado o diâmetro preliminar da polia motriz, que é $265,3 \mathrm{~mm}$. E, tendo o índice de velocidade preliminar e o diâmetro preliminar da polia motriz, com a Equação 3 pode ser encontrado o diâmetro preliminar da polia movida que é de $636,6 \mathrm{~mm}$. Esses valores de diâmetros preliminares das polias devem ser ajustados conforme disponibilidade de polias comerciais, as quais seguem normas específicas. Neste exemplo adotam-se as medidas padrão de polias para correia SPB fornecidas pela [20]. Nesse contexto, os diâmetros são ajustados para: Polia motriz $\mathrm{d}=250 \mathrm{~mm}$; Polia movida $\mathrm{D}=630 \mathrm{~mm}$.

Essa escolha de novos diâmetros de polias é validada verificando a proximidade de alguns dados desejados junto às equações $1,3,4$ e 5 , obtendo-se: nova velocidade linear $V=18,85 \frac{\mathrm{m}}{\mathrm{s}}$; novo índice de velocidade $i=2,52$; nova rotação da polia movida $\omega_{2}=571 \mathrm{rpm}$; comprimento $L=3150 \mathrm{~mm}$ e; distância de centros $C=863 \mathrm{~mm}$. Dessa forma, observando que os novos valores são próximos aos desejados, os diâmetros de polias são aprovados.

Aplicando a recomendação de [3], determina-se que a estimativa inicial para a distância preliminar entre centros das polias, $C_{p}$, devendo ser maior a $630 \mathrm{~mm}$ e menor a $2640 \mathrm{~mm}$. Para este exemplo, adota-se uma distância preliminar entre centros de $900 \mathrm{~mm}$. Com esse valor preliminar é encontrado o comprimento preliminar da correia, $L_{p}$, usando a Equação 4 , obtendo-se um valor de $3222 \mathrm{~mm}$. Consultando o catálogo do fabricante [20], a correia mais próxima ao comprimento preliminar, considerando os diâmetros das polias já selecionadas e o novo índice 
de velocidade, é $L=3150 \mathrm{~mm}$.

Com esse novo comprimento é ajustada a distância entre centros de polias, para tal usa-se a Equação 5 e dessa forma obtém-se uma nova distância entre centros real de $C=863 \mathrm{~mm}$, atendendo à exigência do projeto que solicitava ser menor ou igual a $900 \mathrm{~mm}$.

Como foi selecionada uma correia em V seção SPB, agora deve ser determinada a quantidade de correias a serem usadas. Para tal, com auxílio da Figura 12, ingressa-se o diâmetro da polia motriz (250 mm) e sua rotação (1 $440 \mathrm{rpm})$; encontrando sua potência unitária, $P_{u}=17,63 \mathrm{~kW}$, que é muito abaixo da potência do projeto, $P_{p}=63 \mathrm{~kW}$. Dessa forma, é necessário usar mais de uma correia SPB, e por esse motivo se acrescenta a capacidade de potência de uma correia SPB usando também a Figura 12, onde é ingressado o índice de velocidade $(2,62)$ e a rotação (1 $440 \mathrm{rpm}$ ), para encontrar o acréscimo de potência, $P_{a}=0,72 \mathrm{~kW}$. Assim, a potência básica fica, $P_{b}=18,35 \mathrm{~kW}$.

A seguir, com uso da Equação 6, é encontrado o ângulo de envolvimento da polia mais crítica, ou seja, a polia motriz, seno $\theta_{d}=155$, lembrando que deve ser maior de $120^{\circ}$ [3]. Com esse valor será corrigida a potência básica, $P_{b}$, e para tal é usado o gráfico da Figura 14 para encontrar o fator de correção do ângulo de envolvimento, $C_{\theta} \approx 0,93$.

A potência básica, $P_{b}$, ainda deve ser corrigida usando o comprimento real da correia, $L$, para encontrar o fator de correção de comprimento, $C_{L} \approx 0,98$, por meio do uso da Figura 15, ingressando o tipo de correia e o comprimento real $L=3150 \mathrm{~mm}$.

Ajustada da potência básica, $P_{b}$, com a multiplicação dos fatores de correção, obtém-se a potência real, $P_{r}=16,72 \mathrm{~kW}$.

Assim, a potência de projeto, $P_{d}$, é dividida pela potência real, $P_{r}$, para saber a quantidade de correias necessárias, obtendo o valor de 3,8. Dessa forma, e para garantir o correto funcionamento do sistema de transmissão, é definido que devem ser usadas 4 correias, de código SPB3150X4. Essas 4 correias juntas apresentam uma largura aproximada de $66 \mathrm{~mm}$.

Seguindo a mesma sequência desse exercício, foi realizada a seleção para correias em $\mathrm{V}$ perfil C e 5V, obtendo:

1. Correia em V seção C: código C128X4; diâmetro da polia motriz 279,4 mm; diâmetro da polia movida $762 \mathrm{~mm}$; distância entre centros $801 \mathrm{~mm}$; rotação da polia movida $528 \mathrm{rpm}$; comprimento da correia $3310 \mathrm{~mm}$; ângulo de envolvimento 145; largura que ocupam essas 4 correias $88 \mathrm{~mm}$.

2. Correia em V seção 5V: código 5V118X4; diâmetro da polia motriz 245,1 mm; diâmetro da polia movida 535,9 mm; distância entre centros $873 \mathrm{~mm}$; rotação da polia movida 659 rpm; comprimento da correia 2997 mm; ângulo de envolvimento 161; largura que 
ocupam essas 4 correias $60 \mathrm{~mm}$.

Finalmente, usando o programa CAD [11]; considerando a norma [8]; considerando a norma DIN 6885-1 A que define medidas de canal de chaveta. A seguir é apresentada na Figura 16 uma ilustração do desenho técnico da polia motriz para SPB3150X4.
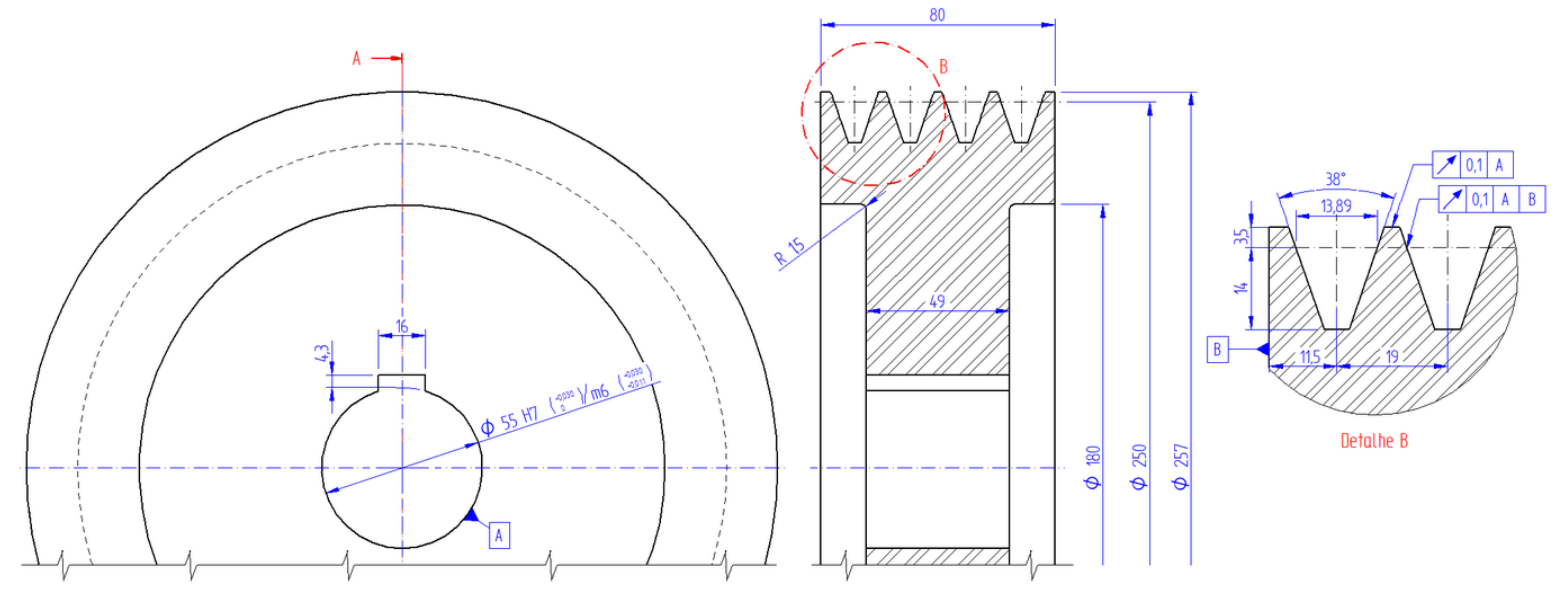

Figura 16: Desenho técnico polia motriz para correias SPB3150X4

\section{Dimensionamento de correias sincronizadas}

O dimensionamento de correias sincronizadas segue um procedimento similar ao já usado para correias perfil em V. As principais mudanças estão no fator de serviço e gráficos de seleção de tipo de correia. Essas informações iniciais de um projeto são apresentadas a seguir usando o catálogo de [4].

Na Tabela 2, em comparação com a Tabela 1, percebe-se que os valores são superiores, ou seja, para uma mesma potência de entrada a potência de projeto será maior nas correias sincronizadas do que nas correias em $\mathrm{V}$.

A seguir na Figura 17, extraída de [4], é apresentado o tipo de correia que pode ser usado, sabendo-se da potência de projeto, lembrando que esse tipo de correias sincronizadas têm dentes trapezoidais. 
Tabela 2: Fator de serviço entre tipo de acionamento e máquina acionada para correias sincronizadoras

\begin{tabular}{|c|c|c|c|c|c|c|}
\hline & Motor & elétrico & $\begin{array}{l}\text { partida } \\
\text { leve }\end{array}$ & Motor & elétrico & $\begin{array}{l}\text { partida } \\
\text { pesada }\end{array}$ \\
\hline $\begin{array}{l}\text { Carga segundo tipo de } \\
\text { máquina acionada }\end{array}$ & $\begin{array}{l}<10 \mathrm{~h} \\
\text { por dia }\end{array}$ & $\begin{array}{l}10-16 \mathrm{~h} \\
\text { por dia }\end{array}$ & $\begin{array}{l}>16 \mathrm{~h} \\
\text { por dia }\end{array}$ & $\begin{array}{l}<10 \mathrm{~h} \\
\text { por dia }\end{array}$ & $\begin{array}{l}10-16 \mathrm{~h} \\
\text { por dia }\end{array}$ & $\begin{array}{l}>16 \quad h \\
\text { por dia }\end{array}$ \\
\hline $\begin{array}{l}\text { Uniforme: Transportadores } \\
\text { de correai leves, bombas } \\
\text { centrífugas, compressor, ven- } \\
\text { tilador e soprador abaixo de } \\
7,5 \mathrm{~kW}\end{array}$ & 1,3 & 1,4 & 1,5 & 1,7 & 1,8 & 1,9 \\
\hline $\begin{array}{l}\text { Choque leve: Agitadores, } \\
\text { bomba rotativa, gerador, } \\
\text { máquinas ferramentas, mistu- } \\
\text { radores, ventilador e soprador } \\
\text { acima de } 7,5 \mathrm{~kW} \text {, transpor- } \\
\text { tador de cascalho, peneira } \\
\text { rotativa }\end{array}$ & 1,4 & 1,5 & 1,6 & 1,8 & 1,9 & 2,0 \\
\hline $\begin{array}{l}\text { Choque médio: elevador de } \\
\text { canecas, máquina de tijolo, } \\
\text { bomba de pistão, máquina } \\
\text { têxtil, moinho martelo, pul- } \\
\text { verizador, transportadores } \\
\text { pesados, prensa, guilhotina, } \\
\text { máquina de borracha, peneira } \\
\text { vibratório }\end{array}$ & 1,7 & 1,8 & 1,9 & 2,0 & 2,1 & 2,2 \\
\hline $\begin{array}{l}\text { Choque pesado: Triturador, } \\
\text { moinho de bolas, guindastes, } \\
\text { extrusores }\end{array}$ & 1,9 & 2,0 & 2,1 & 2,3 & 2,4 & 2,5 \\
\hline
\end{tabular}




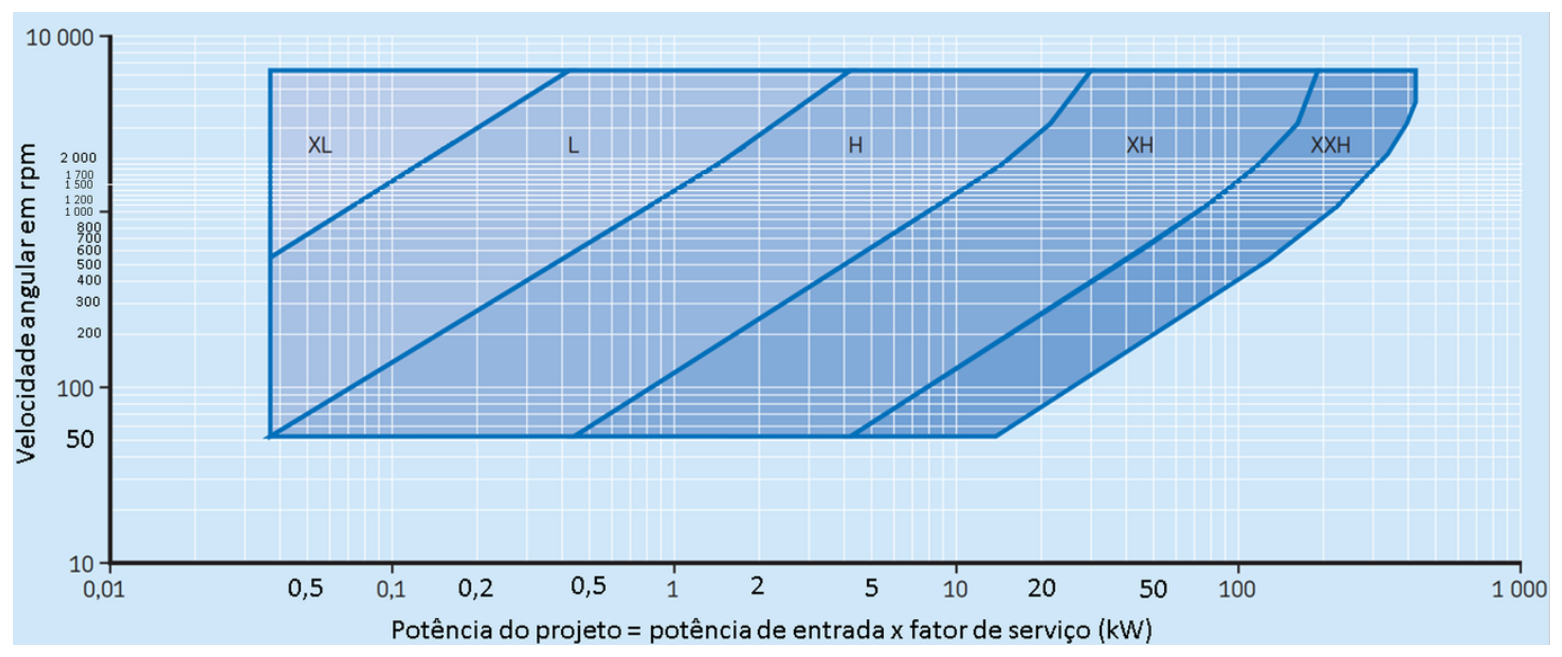

Figura 17: Gráfico para seleção de correia tipo XL, L, H, XH e XXH

Na Figura 18, extraída de [4], são apresentadas as posibilidades de correias sincronizadas, lembrando que os dentes dessas correias são arredondados.

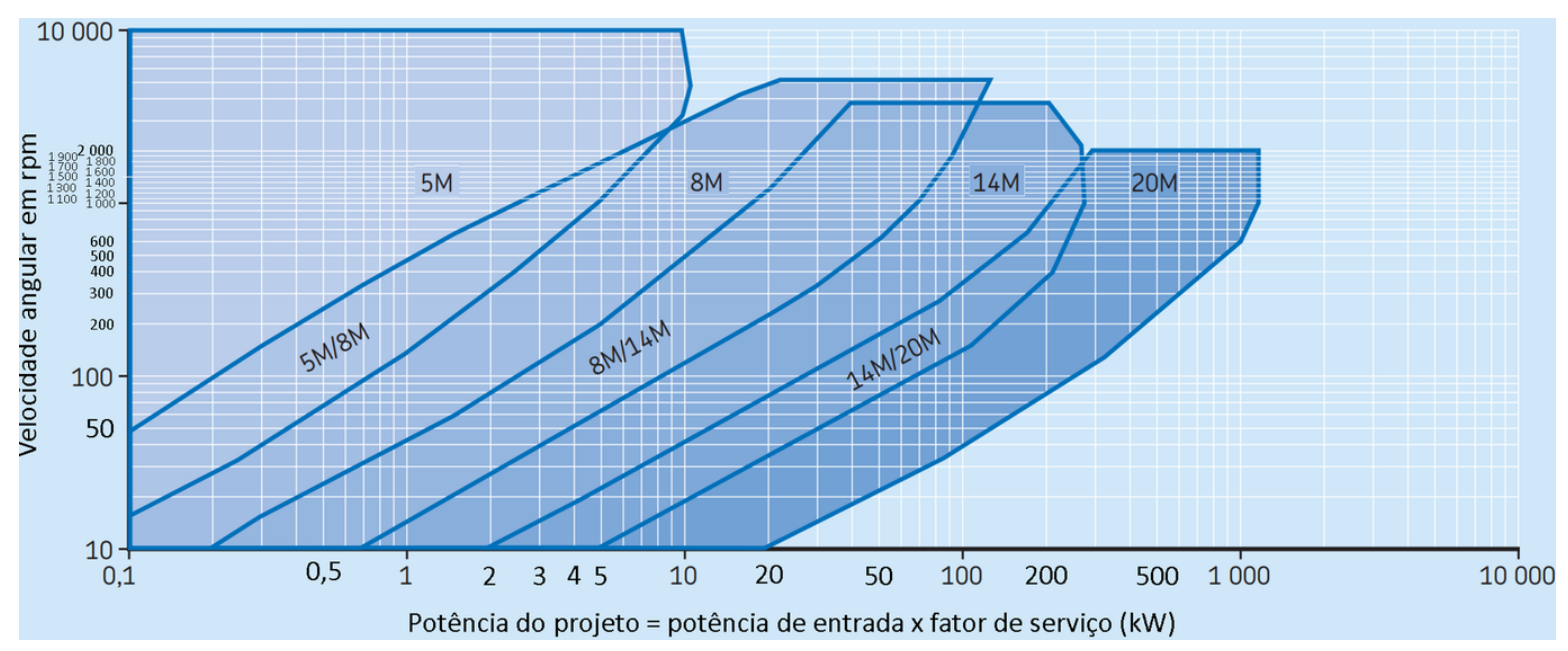

Figura 18: Gráfico para seleção de correia tipo 5M, 8M, 14M e 20M

Para maior entendimento do procedimento para a seleção de uma correia sincronizadora será calculado o mesmo exercício anteriormente apresentado.

Da Tabela 2 agora o fator de serviço é 2,0; agora a potência de projeto é $90 \mathrm{~kW}$. Usando os gráficos das figuras 17 e 18 verifica-se que pode ser escolhida uma correia XH ou 14M. Também, sabendo as rotações da polia motriz e a desejada para a polia movida, pode ser encontrado o índice de velocidade usando a Equação 3, sendo $i_{p}=2,4$. E, com a Equação 1, agora considerando que uma velocidade linear nominal é $10 \mathrm{~m} / \mathrm{s}$, pode ser encontrado o diâmetro preliminar da polia motriz, $d_{p}=132,6 \mathrm{~mm}$. Na sequência, com a Equação 3 pode ser encontrado 
o diâmetro prliminar da polia movida, $D_{p}=318,3 \mathrm{~mm}$.

A seguir, são realizados os cálculos para a seleção de uma correia síncrona 14M. Essa escolha, é devido, principalmente, a que a ISO retirou a norma especifica de correias trapezoidais e disponibiliza apenas informação para correias síncronas circulares.

Assim, usando o catálogo do fabricante [20], os diâmetros padronizados são: $d=133,69 \mathrm{~mm}$ com 30 dentes, e $D=320,86 \mathrm{~mm}$ com 72 dentes.

Usando a Equação 3 atualiza-se o índice de velocidade, sendo $i=2$, 4, e também com essa mesma equação encontra-se a rotação real da polia movida, $\omega_{2}=599,99 \mathrm{~mm}$. Tanto o índice de velocidade como a rotação da polia movida, são bem próximas aos valores desejados de projeto.

A continuação é calculado o comprimento da correia, para tal, primeiramente determina-se a distância preliminar entre centros, seguindo a recomendação de [3], ou seja, essa distância deve ser maior de $321 \mathrm{~mm}$ e menor de $1364 \mathrm{~mm}$. Para ser essa distância parecida ao sistema que foi calculado para correia em $\mathrm{V}$, considera-se $C_{p}=900 \mathrm{~mm}$.

Com a Equação 4 encontra-se o comprimento preliminar da correia, $L_{P}=2523 \mathrm{~mm}$. Consultando o fornecedor de correias [20], o comprimento mais próximo disponível para esse tipo de correia é de $L=2450 \mathrm{~mm}$, com 175 dentes. Com esse comprimento real, usando a Equação 5, encontra-se a distância real entre centros, $C=863,1 \mathrm{~mm}$. Lembrando que essa distância deve ser menor ou igual a $900 \mathrm{~mm}$, ou seja, atende à solicitação de projeto.

Na sequência, com a Equação 6 encontra-se o ângulo de envolvimento, $\theta_{d}=168$, e usando o gráfico da Figura 14 encontra-se um fator de correção $C_{\theta} \approx 0,97$.

Por outro lado, tendo o comprimento real da correia, com a Figura 19 encontra-se o fator de comprimento $C_{L}=0,95$. 


\begin{tabular}{|c|c|c|c|c|}
\hline $\begin{array}{l}\text { Comprimento } \\
\text { da correia }\end{array}$ & $5 \mathrm{M}$ & or de co & $14 \mathrm{M}$ & $\begin{array}{l}X L \\
L \\
H \\
X H\end{array}$ \\
\hline $\mathrm{mm}$ & - & & & \\
\hline 425 & 0,80 & - & - & 1,00 \\
\hline 535 & 0,90 & - & - & 1,00 \\
\hline 600 & 1,00 & - & - & 1,00 \\
\hline 800 & 1,10 & - & - & 1,00 \\
\hline 890 & 1,20 & - & - & 1,00 \\
\hline 1050 & 1,30 & - & - & 1,00 \\
\hline 1190 & - & 0,80 & - & 1,00 \\
\hline 1200 & - & 0,90 & - & 1,00 \\
\hline 1420 & - & 1,00 & - & 1,00 \\
\hline 1610 & - & 1,10 & - & 1,00 \\
\hline 1760 & - & 1,20 & - & 1,00 \\
\hline 1890 & - & - & - & 1,00 \\
\hline 2000 & - & - & 0,90 & 1,00 \\
\hline 2450 & - & - & 0,95 & 1,00 \\
\hline 2500 & - & - & 1,00 & 1,00 \\
\hline 3150 & - & - & 1,05 & 1,00 \\
\hline 3400 & - & - & 1,10 & 1,00 \\
\hline
\end{tabular}

Figura 19: Fator de correção para comprimento de correia síncrona

A seguir usando o gráfico da Figura 20, que é uma adaptação de [4], encontra-se a potência básica, $P_{b}$, da correia selecionada. Para tal, deve ser ingressado, na parte superior, o diâmetro da polia motriz, $d=133,69 \mathrm{~mm}$, e na coluna do lado esquerdo a sua rotação de $1440 \mathrm{rpm}$, encontrando a potência básica $P_{b}=21,22 \mathrm{~kW}$. 


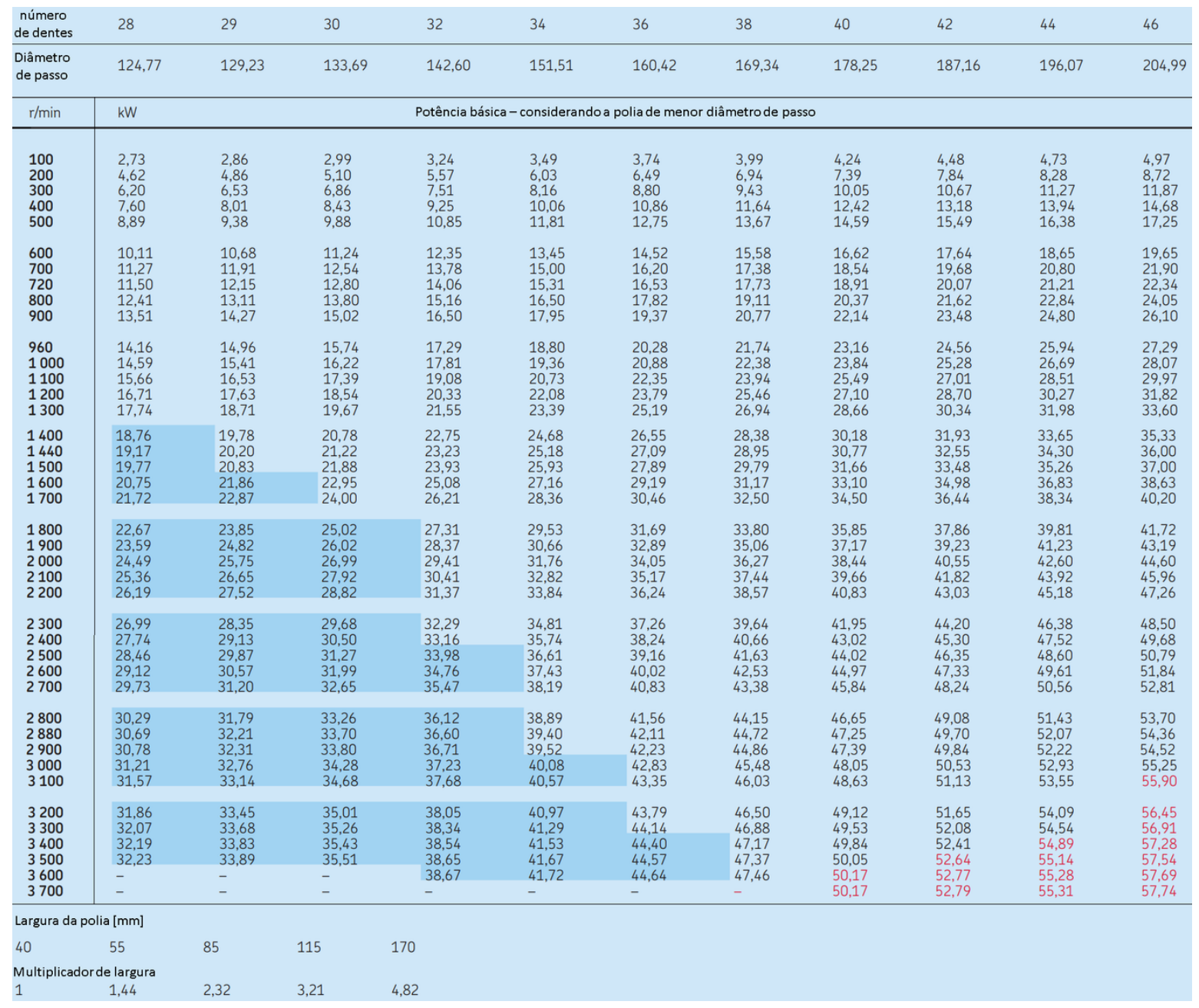

Figura 20: Potência básica de correias 14M

Agora a potência básica, $P_{b}$, é multiplicada pelos fatores de correção de envolvimento e comprimento, obtendo-se uma potência real $P_{r}=19,55 \mathrm{~kW}$. lembrando que a potência de projeto é $P_{d}=90 \mathrm{~kW}$, ou seja, a potência real está abaixo da potência de projeto. Assim, $\frac{P_{d}}{P_{r}}=4,6$, esse valor é denominada agora de multiplicador de largura. Verificando ainda a Figura 20, na parte inferior dessa Tabela, encontra-se que o valor mais próximo é de 4,82, ou seja, esse valor indica que a largura da correia deve ser de $170 \mathrm{~mm}$. Finalmente, especifica-se que a correia a ser selecionada é uma correia 2450-14M-170.

\section{Conclusões}

No estudo de caso apresentado, entre as correias em V de seção SPB, C, 5V e a síncrona 14M percebe-se: 
Tabela 3: Comparativo entre correias SPB, C, 5V e 14M

\begin{tabular}{lcccc}
\hline & \multicolumn{4}{c}{ Tipos de correias } \\
\hline Descrição & SPB & C & $\mathbf{5 V}$ & $\mathbf{1 4 M}$ \\
\hline Diâmetro de passo polia motriz [mm] & 250,0 & 279,4 & 245,1 & 113,7 \\
Diâmetro de passo polia movida [mm] & 630,0 & 762,0 & 535,9 & 320,9 \\
Distância entre centro [mm] & 863 & 801 & 873 & 863 \\
Comprimento [mm] & 3150 & 3310 & 2997 & 2450 \\
ângulo de envolviemnto & 155 & 145 & 164 & 168 \\
Largura das correias [mm] & 66 & 88 & 60 & 170 \\
\hline
\end{tabular}

1. A polia para correia $\mathrm{C}$, possui o maior diâmetro de polia motriz, sendo que a SPB é $11 \%$ menor, a 5V $12 \%$ menor e a 14M 59\% menor;

2. Pouca diferença quando avaliada a distância entre centros. $\mathrm{O}$ conjunto de polias $5 \mathrm{~V}$ é a que maior distância apresenta, sendo que a SPB e 14M são $1 \%$ menor e a C $8 \%$ menor;

3. As polias $14 \mathrm{M}$ são as que apresentam maior largura de correia, sendo que a $\mathrm{C}$ é $48 \%$ menor, a SPB $61 \%$ menor e a 5V 65\% menor.

Assim, considerando o espaço que ocuparia o sistema de transmissão, o conjunto de correias $\mathrm{SPB}$, em média, é o que ocupa menos espaço. Na Tabela 3, mostram-se os principais valores obtidos para cada correia que poderia ser selecionada para o sistema de transmissão do estudo de caso.

Outro fator importante para a escolha do tipo de correia depende do valor de aquisição, visto que pode ser um fator importante em função do orçamento que se possui para o investimento financeiro do projeto de um determinado equipamento mecânico. Também a escolha pode depender do custo que gerará cada correia, destacando que, segundo a teoria, as correias estreitas em V e sincronizadas precisam de menos manutenção.

É importante ressaltar que o presente trabalho, não fez o levantamento do custo de cada correia e polia de transmissão, visto que esse valor pode variar dependendo da região ou época de consulta. Mas, destaca-se que dito levantamento deve ser realizado antes de validar um projeto de transmissão por correias flexíveis.

Finalmente, lembra-se que o presente trabalho apresentou o cálculo de seleção de correias de transmissão consideradas como as mais comuns, acessíveis e padronizadas por norma ISO, mas, outros tipos de correias podem ser consultados nos catálogos de fabricantes, tais como: [20], [5], [17], entre outros. 


\section{Referências}

[1]J. Wicker and K. Lewis, Introdução à Engenharia Mecânica, 2nd ed. Cengage Learning, 2015.

[2]S. Melconian, Fundamentos de Elementos de Máquinas, Transmissões, Fixações e Amortecimento. Editora Saraiva, 2019.

[3]R. L. Mott, Machine elements in mechanical design, 5th ed. Pearson, 2013.

[4]G. SKF, “SKF POWER TRANSMISSION - belts”, SKF group, 1, 2012.

[5]C. GATES, “Gates Industrial Belt”, Gates Corporations, 2015.

[6]S. ISO 4184, "Belt drives - Classical and narrow V-belts - Lengths in datum system", International Organization for Standardization, 1992.

[7]S. ISO 1813, "Belt drives - V-ribbed belts, joined V-belts and V-belts including wide section belts and hexagonal belts - Electrical conductivity of antistatic belts: Characteristics and methods of test", International Organization for Standardization, 2014.

[8]S. ISO 4183, "Belt drives - Classical and narrow V-belts - Grooved pulleys (system based on datum width)", International Organization for Standardization, 1995.

[9]S. ISO 5290, "Belt drives — Grooved pulleys for joined narrow V-belts - Groove sections 9N/J, 15N/J and 25N/J”, International Organization for Standardization, 2001.

[10]S. DIN 7753-1, "Endless narrow V-belts for mechanical engineering purposes; dimensions", Deutsches Institut für Normung, 1988.

[11]S. Solid Edge, "Solid Edge for Educators", PLM Siemens, 2020.

[12]S. ISO 9982, "Belt drives - Pulleys and V-ribbed belts for industrial applications - PH, PJ, PK, PL and PM profiles: dimensions", International Organization for Standardization, 1998.

[13]I. S. O. ISO 19347, "Synchronous belt drives - Imperial pitch trapezoidal profile system — Belts and pulleys", International Journal of Mechanical Sciences, 2015.

[14]S. ISO 5296, "Synchronous belt drives - Belts with pitch codes MXL, XXL, XL, L, H, $\mathrm{XH}$ and XXH - Metric and inch dimensions", International Journal of Mechanical Sciences, 2012.

[15]S. ISO 5294, "Synchronous belt drives - Pulleys", International Organization for Standardization, 2012. 
[16]S. ISO 13050, "Synchronous belt drives - Metric pitch, curvilinear profile systems G, H, R and S, belts and pulleys", International Organization for Standardization, 2014.

[17]Optibel, “TECHNICAL MANUAL RUBBER TIMING BELT DRIVES”, Arntz OptIBelt Group, 2020.

[18]S. ISO 9563, "Belt drives - Electrical conductivity of antistatic endless synchronous belts — Characteristics and test method", International Organization for Standardization, 2015.

[19]R. G. Budynas and J. K. Nisbett, Shigley's Mechanical Engineering Design, 10th ed. McGraw-Hill Education, 2014.

[20]G. SKF, “SKF Power Transmission products”, SKF Group, 2016. 